\title{
Intermediate compartment (IC): from pre-Golgi vacuoles to a semi- autonomous membrane system
}

\author{
Jaakko Saraste $^{1}$ D $\cdot$ Michaël Marie $^{1}$ \\ Accepted: 27 August 2018 / Published online: 1 September 2018 \\ (c) The Author(s) 2018
}

\begin{abstract}
Despite its discovery more than three decades ago and well-established role in protein sorting and trafficking in the early secretory pathway, the intermediate compartment (IC) has remained enigmatic. The prevailing view is that the IC evolved as a specialized organelle to mediate long-distance endoplasmic reticulum (ER)-Golgi communication in metazoan cells, but is lacking in other eukaryotes, such as plants and fungi. However, this distinction is difficult to reconcile with the high conservation of the core machineries that regulate early secretory trafficking from yeast to man. Also, it has remained unclear whether the pleiomorphic IC components-vacuoles, tubules and vesicles-represent transient transport carriers or building blocks of a permanent pre-Golgi organelle. Interestingly, recent studies have revealed that the IC maintains its compositional, structural and spatial properties throughout the cell cycle, supporting a model that combines the dynamic and stable aspects of the organelle. Moreover, the IC has been assigned novel functions, such as cell signaling, Golgi-independent trafficking and autophagy. The emerging permanent nature of the IC and its connections with the centrosome and the endocytic recycling system encourage reconsideration of its relationship with the Golgi ribbon, role in Golgi biogenesis and ubiquitous presence in eukaryotic cells.
\end{abstract}

Keywords Secretory pathway $\cdot$ Golgi ribbon $\cdot$ ER-Golgi intermediate compartment (IC) $\cdot$ Endosome $\cdot$ COPI $\cdot$ Rab1/Ypt1

\section{Introduction}

The intermediate compartment (IC)—a dynamic membrane system consisting of peripheral and central domains-functions in protein sorting and bi-directional trafficking at the ER-Golgi interface of mammalian cells. The IC elements associate with ER exit sites (ERES), where they receive newly synthesized proteins and lipids from COPII-coated vesicles budding off the ER membrane. While it is generally accepted that the subsequent anterograde delivery of ER-derived cargo from ERES to the cis-face of the Golgi apparatus depends on motor-dependent movements of the IC elements along cytoskeletal filaments, the mechanisms of cargo transfer at the end stations of the ER-Golgi itinerary-at ERES and cis-Golgi-remain poorly understood (Hanna et al. 2018; Lorente-Rodriquez and; Barlowe 2011;

Jaakko Saraste

jaakko.saraste@uib.no

1 Department of Biomedicine and Molecular Imaging Center (MIC), University of Bergen, Jonas Lies vei 91, 5009 Bergen, Norway
Saraste and Marie 2016; Zanetti et al. 2012). This has left key questions regarding the nature of the IC and its role in the secretory pathway unanswered. As a result, although the existence of the IC as a discrete pre-Golgi entity is well recognized, it is still debated whether it represents a transient or permanent structure.

However, the currently prevailing model of the IC emphasizes its transient character. Accordingly, the IC is viewed as a collection of pleiomorphic transport intermediates that arise at ERES via the coalescence of ER-derived COPII vesicles, acquire Golgi-like properties as they move to the cell center and, finally, upon their arrival at the cis-face of the Golgi stacks assume a flat cisternal shape. Supporting this view, the IC elements recruit COPI coats, which are known to function in the sorting and retrograde transfer of selected components, such as lipids, cargo receptors and escaped ER proteins, to the ER (Rabouille and Klumperman 2005). Extensive membrane recycling by COPI vesicles is thought to alter the composition of the IC elements, resulting in their gradual transformation into cis-Golgi cisternae. Indeed, an analogous COPI-dependent maturation process is the favoured mechanism for cargo progression across the Golgi 
stacks to the trans-Golgi network (TGN) (Nakano and Luini 2010). However, the exclusive retrograde function of COPI vesicles at the level of the IC and the Golgi stacks has been challenged by results suggesting anterograde role(s) for the COPI coats (Hosobuchi et al. 1992; Love and Kreis, 1998; Orci et al. 1997; Park et al. 2015; Pepperkok et al. 1993; Peter et al. 1993; Malsam et al. 2005). To complicate matters further, COP-independent tubular intermediates have been implicated in retrograde transport at the ER-Golgi boundary (Bottanelli et al. 2017; Heffernan and Simpson 2014; Sengupta et al. 2015).

The organization of the ER-Golgi interface varies in different eukaryotic cells (Brandizzi and Barlowe 2013). In vertebrate cells, the ER network extends throughout the entire cytoplasm, while the Golgi stacks are positioned near the cell center, linked together into a continuous ribbon around the centrosome (Gosavi and Gleeson 2017). Thus, a large proportion of the ERES - in cultured mammalian cells about half of them-are found at the cell periphery, whereas the rest associate with the central IC elements residing next to the Golgi ribbon (Bannykh et al. 1996; Hammond and Glick 2000; Stephens 2003). A precondition of this spatial arrangement is the long distance movement of the IC elements from peripheral ERES to the Golgi region along microtubule (MT) tracks. A different organization of the early secretory pathway is encountered in invertebrates (e.g., D.melanogaster and C. elegans), plants and fission yeasts (e.g., $P$. pastoris). In these cells, the individual Golgi stacks remain separate and reside next to the widespread ERES, establishing compact secretory units for short-range ER-Golgi communication (Brandizzi and Barlowe 2013). Strikingly, the secretory system of the budding yeast $S$. cerevisiae consists of tubular networks, but lacks Golgi stacks (Rambourg et al. 2001; Suda et al. 2018). These findings have led to the idea that the IC developed late in evolution to solve the logistics problems posed by the large size of vertebrate cells (Brandizzi and Barlowe 2013). Its apparent absence in many eukaryotes, such as the important model organism S. cerevisiae, has contributed to the view of the IC as a transient structure rather than a discrete organelle.

However, the proposed compartmental diversity of the early secretory pathway is not in agreement with the conservation of protein machineries that operate in ER-Golgi trafficking across the eukaryotic kingdom (Barlowe and Miller 2013; Bonifacino and Glick 2004; Klute et al. 2011; Lee et al. 2004). Indeed, recent electron microscopic (EM) tomography analysis has suggested the presence of the IC in the compact secretory system of $C$. elegans (Hanna et al. 2018; Witte et al. 2011), and certain cell types in $D$. melanogaster lack Golgi stacks, but contain IC-like tubulovesicular membrane clusters (Kondylis and Rabouille 2009). Moreover, it has been suggested that plants contain a cis-Golgi compartment, which is analogous to the IC and functions in the biogenesis of the Golgi stacks (Day et al. 2013; Donohoe et al. 2013; Ito et al. 2018). In general, defining compartments based on their transport machineries and the traffic patterns they support (Day et al. 2013), raises the possibility that the tubular cis-Golgi network of S. cerevisiae and the mammalian IC are equivalent structures as well (Kurokawa et al. 2014; Marie et al. 2008; Suda et al. 2018).

This review makes an attempt to provide the reader a concise summary on the structural, functional and dynamic properties of the IC in mammalian cells. We discuss recent data on novel functions of the IC that are not directly related to ER-Golgi trafficking. Since the nature of the IC remains a matter of dispute, it is of interest to take another look at the different models of this compartment, which are based on the employment of various reporters to visualize its dynamics in living cells. Interestingly, imaging of the IC during different stages of the cell cycle suggests that it—despite being dynamic - represents a stable organelle. Regarding the present discussion, of particular importance are the recently established permanent connections of the IC elements with the recycling endosomes and the centrosome (Bowen et al. 2017; Marie et al. 2009, 2012). Based on these findings, we propose a model on the role of the stable IC elements and recycling endosomes as "linker compartments" in the Golgi ribbon, operating in the biogenesis of the Golgi stacks. This model can also help to clarify the relationship of the secretory systems of mammalian and yeast cells.

However, since a historical sketch can be informativeparticularly considering a cellular component as enigmatic as the IC-we start by recalling the developments that lead to the placement of this compartment on the map of the cell.

\section{The early days of the IC}

The early 1980s marked an exciting period in the membrane traffic field. Endosomes had just been identified and initially characterized as intermediates in the pathway that leads from the plasma membrane (PM) to lysosomes (Mellman 2006). The striking geometry of endosomes - that is, their division into vacuolar and tubular domains - and their luminal acidification were implicated in the sorting of internalized molecules for recycling back to the PM or delivery for lysosomal degradation. Similarly, acidification turned out to be important in the secretory pathway, ensuring the correct sorting of secretory proteins in the trans-Golgi region to constitutive and regulated post-Golgi carriers (Burgess and Kelly 1987). Regarding pre-Golgi events, two-way traffic between the transitional ER elements-now commonly referred to as ERES-and the cis-Golgi was thought to involve small transport vesicles (Palade 1975). George Palade's vesicle shuttle hypothesis became the paradigm for membrane traffic in general, gaining support, for example, 
from the demonstration of the role of clathrin-coated vesicles in endocytic uptake of molecules at the PM (Robinson 2015). Furthermore, ER-Golgi transport was considered an MT-independent short distance transport step, involving the transfer of newly synthesized proteins from the centrally located ERES to the nearby cis-Golgi cisternae (Kelly 1990).

An increased appreciation of the more complex membrane organization of the ER-Golgi boundary was the outcome of multiple lines of research (for reviews see Balch 1990; Bonatti and Torrisi 1993; Hauri and Schweizer 1992; Huttner and Tooze 1989; Lippincott-Schwartz 1993; Pelham 1989; Saraste and Kuismanen 1992). A key methodological development was the introduction of membrane viruses as tools in membrane traffic, allowing the fusion of genetics and morphology. Temperature-sensitive (ts) mutants of vesicular stomatitis (VSV ts-O45) and Semliki Forest virus (SFV ts-1), carrying reversible folding defects in their membrane glycoproteins, allowed the application of immunocytochemistry to follow the synchronized movement of the proteins from the ER to the PM, following the shift of the cells from restrictive to permissive temperature (Bergman et al. 1981; Saraste and Hedman 1983). As low-temperature incubation had been shown to affect specific steps of both endocytic and secretory transport (Marsh and Helenius 1980; Matlin and Simons 1983), it was of interest to combine such incubations with temperature shift experiments using viral ts-mutants to achieve more detailed mapping of the early secretory pathway. Interestingly, immuno-EM of SFV ts- 1 infected cells shifted from 39 to $15^{\circ} \mathrm{C}$ showed that the viral membrane proteins exit the ER, but accumulate in large vacuoles (up to $0.5 \mu \mathrm{m}$ in diameter), tubules and vesicles both in the cis-Golgi region and more peripheral locations. Light microscopic (LM) studies revealed a scattered distribution of these structures throughout the cytoplasm, a pattern distinct from that of the ER and Golgi (Kuismanen and Saraste 1989; Saraste and Kuismanen 1984; see also Fig. 1). The SFV proteins arrested at $15{ }^{\circ} \mathrm{C}$ contained highmannose oligosaccharides, indicating lack of processing by Golgi enzymes. Importantly, the transport block was reversible and the viral proteins entered the Golgi stacks within minutes after shifting the cells to permissive temperature, indicating that the vacuoles represent normal intermediates in the secretory pathway.

Biochemical and immunocytochemical studies showed that the transport of VSV tsO45 glycoproteins is similarly affected at $15{ }^{\circ} \mathrm{C}$ (Balch et al. 1986; Bonatti et al. 1989). In addition, temperature shift experiments with both VSV and SFV mutants provided evidence for the role of the tubular extensions of the pre-Golgi vacuoles in the entry of viral glycoproteins to the Golgi stacks (Saraste and Kuismanen 1984; Trucco et al. 2004). Indeed, as the pre-Golgi elements turned out to consist of interconnected vacuolar and tubular domains, resembling endosomes in morphology, the term "exosome" was proposed for these novel structures (Balch 1990; Saraste and Kuismanen 1984). In hindsight, taking into account the striking similarities of the IC and endosomal networks revealed by subsequent studies, it seems unfortunate that this term was not permanently adopted to designate these pre-Golgi structures, but instead refers today to the luminal vesicles of endosomes released from different cell types (van Niel et al. 2018).

Subsequent studies have shown that the transport of membrane and soluble secretory proteins is similarly affected at 15-16 ${ }^{\circ} \mathrm{C}$ (Blum et al. 2000; Saraste et al. 1986; Trucco et al. 2004). In general, ever since its introduction, numerous studies have employed the reversible $15-16^{\circ} \mathrm{C}$ temperature block to follow trafficking or modification of proteins in the early secretory pathway, or to synchronize the passage of cargo across the Golgi stacks (Lavieu et al. 2013, 2014; Volchuk et al. 2000; Trucco et al. 2004). However, even today the precise mechanism of the low-temperature block remains unknown. A simple explanation is that temperature reduction, by slowing down transport in general, causes a traffic jam at crossroad sites, where multiple pathways meet (Kuismanen and Saraste 1989). However, the increased tubulation of membranes during $15-16{ }^{\circ} \mathrm{C}$ incubation or shortly after shifting cells to $37{ }^{\circ} \mathrm{C}$ (Ben-Tekaya et al. 2005; Blum et al. 2000; Martinez-Alonso et al. 2005; Palokangas et al. 1998; Simpson et al. 2006) suggests more specific effects on the transport machinery. Indeed, a recent study showed that the activation of Golgi-localized GTPases, such as Arf1, is inhibited at low temperature, resulting in the release of some of their effectors from membranes (Gilbert et al. 2018).

Independent proof for the existence of a distinct pre-Golgi compartment came from EM studies of coronavirus-infected cells showing the early budding of progeny virus particles into a smooth membrane compartment at the ER-Golgi interface (Tooze et al. 1984). Interestingly, initiation of O-glycosylation of the viral membrane $(\mathrm{M})$ protein, by addition of N-acetyl-galactosamine (GalNAc), was suggested to take place in this novel compartment, making it reactive for the GalNAc-specific lectin Helix pomatia (Tooze et al. 1988; Krijnse-Locker et al. 1994). Subsequent studies verified that the coronavirus "budding compartment" corresponds to the IC (Klumperman et al. 1994) and also revealed that the intracellular site of virus maturation is determined by the retention of viral M protein at the cis-side of the Golgi stacks (Machamer et al. 1990). In addition, we know today that the enzyme responsible for the addition of GalNAc (GalNAcT2) cycles between the Golgi and the IC (Jarvela and Linstedt 2012), and under certain conditions-including perhaps viral infection-can accumulate in the latter compartment, making it strongly positive for Helix pomatia (Gill et al. 2010). Besides coronaviruses, the IC has been suggested to support the intracellular maturation of a number of virus 

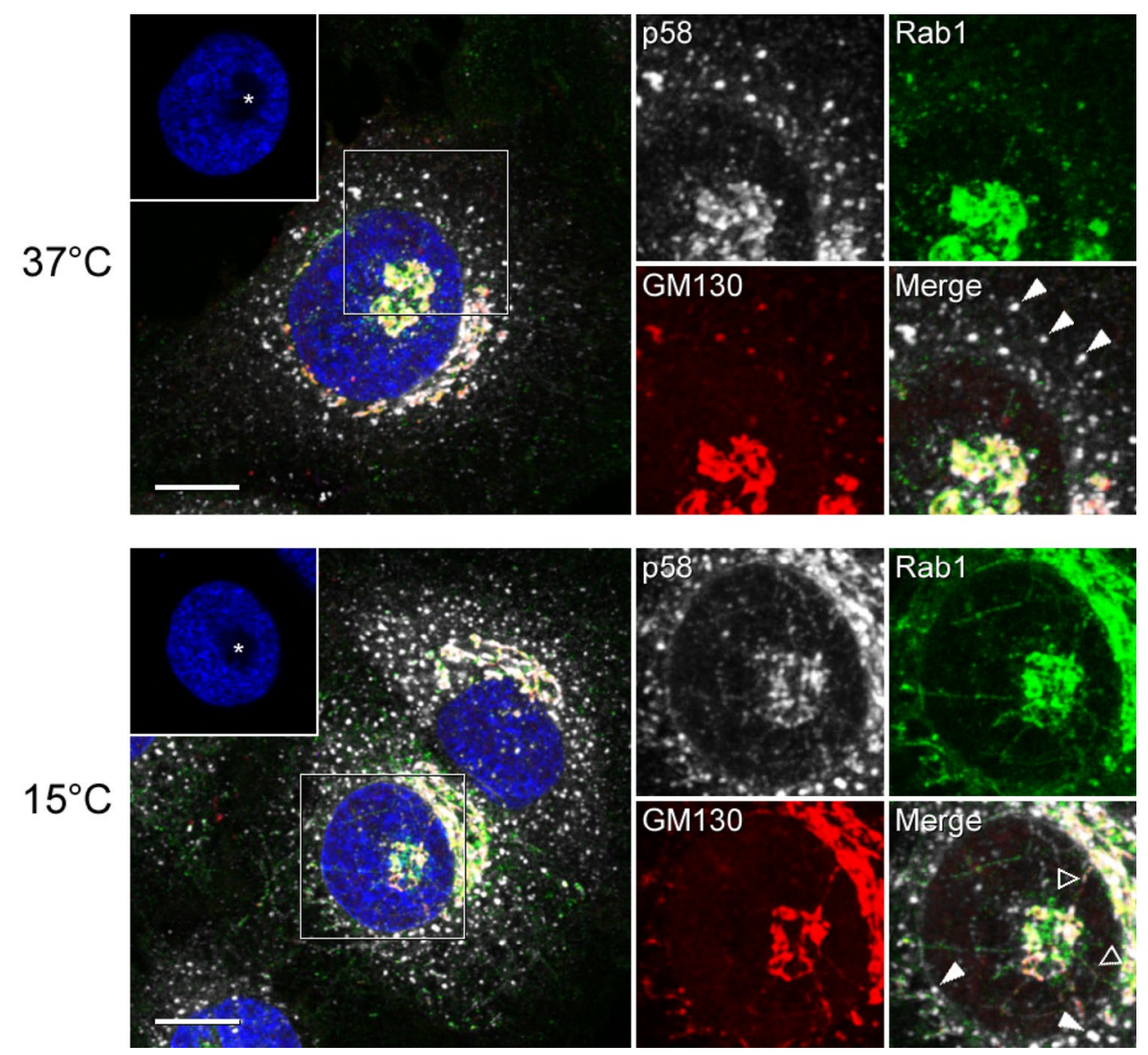

Fig. 1 Distribution of the IC as studied by confocal microscopy. Normal rat kidney (NRK) cells stably expressing GFP-Rab1 were kept at $37{ }^{\circ} \mathrm{C}$ or shifted for $3 \mathrm{~h}$ to $15^{\circ} \mathrm{C}$, followed by staining with antibodies against p58 and GM130, as well as DAPI (to visualize the nuclei). The three IC/cis-Golgi proteins co-localize in the Golgi area, the pericentrosomal domain of the IC (BRC), as well as peripheral IC elements (white arrowheads) that pile up-or become more readily detectable-in the cells shifted to $15^{\circ} \mathrm{C}$. The overlap is not com-

types, including bunya-, entero-, flavi-, picorna- and vacciniaviruses (Hsu et al. 2010; Jäntti et al. 1997; Miller and Krijnse-Locker 2008; Risco et al. 2002).

The discovery of the mechanism of retention of luminal ER proteins equipped with the C-terminal tetrapeptide KDEL-signal (HDEL in yeast) opened up for the operation of a special sorting compartment at the ER-Golgi boundary. Namely, it was suggested that these abundant molecular chaperones, such as BiP and PDI, are retained in a dynamic process that involves their continuous escape from the ER lumen and retrieval from a post-ER location (Munro and Pelham 1987; Pelham 1989). The $15^{\circ} \mathrm{C} /$ coronavirus budding compartment was proposed as the "salvage compartment" (Warren 1987) from which the escaped KDEL-proteins are returned to the ER. Furthermore, the attachment of the KDEL-signal to a lysosomal enzyme and the application of the $15{ }^{\circ} \mathrm{C}$ block gave evidence that the phosphotransferase plete due to enrichment of these proteins to different IC subdomains. Low temperature also boosts the tubulation of the IC, for example, the formation of tubular connections between the BRC and the Golgi ribbon (open arrowheads). The insets with single DAPI staining highlight the nuclear "pockets" (asterisks), where the BRC resides after its relocation under the nucleus. The anti-GM130 antibodies were kindly provided by Francis Barr, Department of Biochemistry, University of Oxford, UK. Bars: $10 \mu \mathrm{m}$

initiating the formation of the mannose-6-phosphate lysosomal targeting signal resides in the IC (Pelham 1988; Lazzarino and Gabel 1988). Subsequently, the yeast and mammalian KDEL-receptors were identified (Lewis and Pelham 1990; Semenza et al. 1990) and the latter was found to predominantly localize to the IC/cis-Golgi (Griffiths et al. 1994; Tang et al. 1993; see also Fig. 2a). The recycling of the KDEL receptor at the ER-Golgi boundary is now known to take place in COPI vesicles (Majoul et al. 2001; Martínez-Menárguez et al. 1999; Orci et al. 1997). Similarly, integral membrane proteins that cycle between the ER and the IC/cis-Golgi were shown to contain dilysine (KKXX)-signals in their cytoplasmic C-terminal tails, which bind directly to COPI coats (Cosson and Latourneur 1997; Jackson et al. 1990; Nilsson et al. 1989). 
Fig. 2 The KDEL-receptor localizes to the IC throughout the cell cycle. Confocal microscopic localization of the KDEL-receptor in GFPRab1-expressing NRK cells at interphase (a) or metaphase (b). During interphase, the receptor and Rab1 largely overlap in IC elements at the cell periphery and in the juxtanuclear Golgi region. Both proteins are also present in the BRC (framed area), but show preferential enrichment to its globular (vacuolar) and tubular subdomains, respectively. Notably, they also co-localize to mitotic IC elements, which maintain their spatial organization at metaphase, being present both at the cell periphery and in the pericentrosomal region close to the spindle poles. Antibodies against the KDEL-receptor were kindly provided by Irina Majoul, Institute of Biology, University of Lübeck, Germany. The images in (b) were reproduced from Marie et al. (2012). Bars: $10 \mu \mathrm{m}$ a
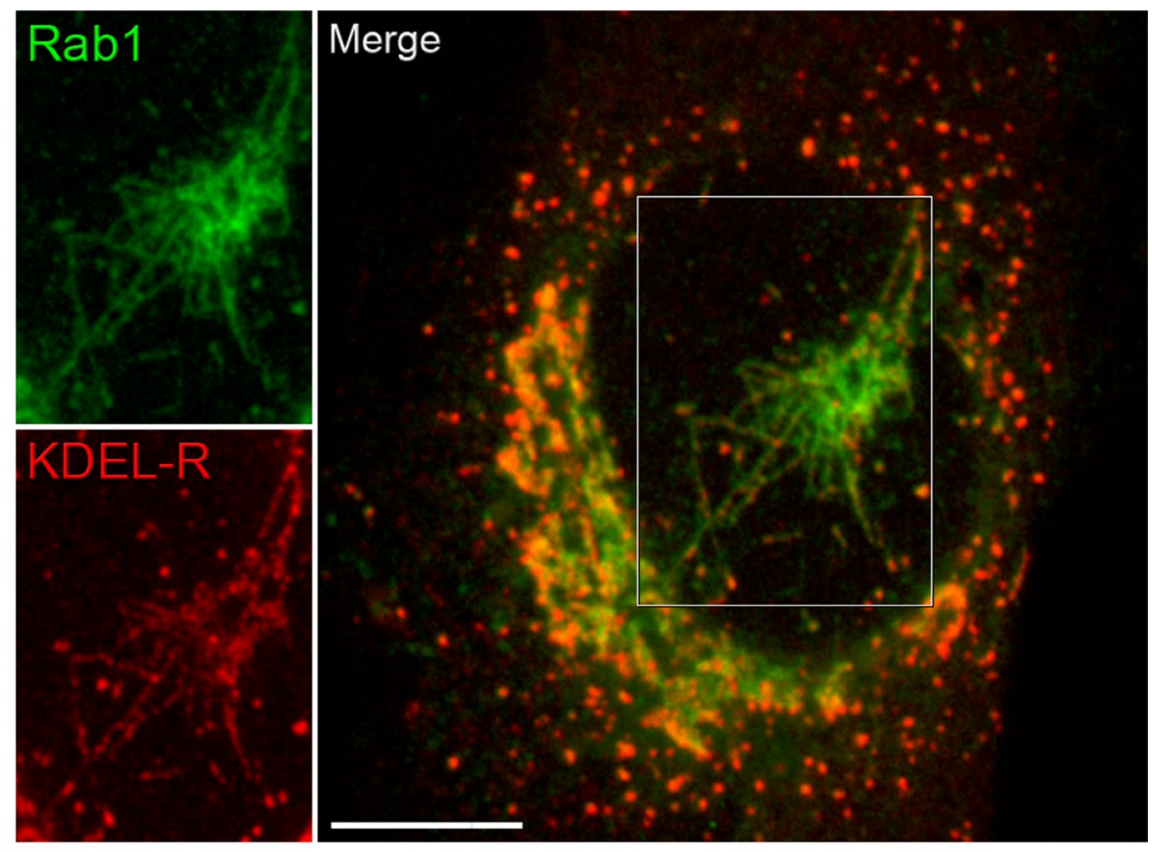

b

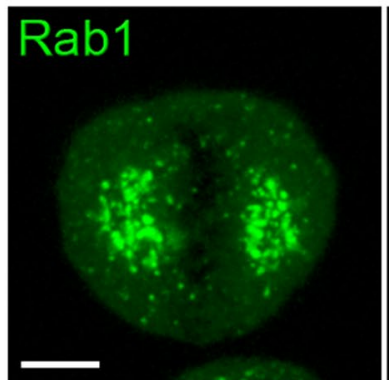

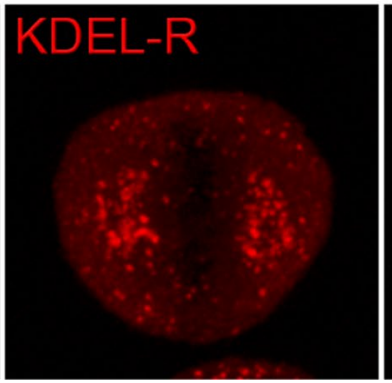

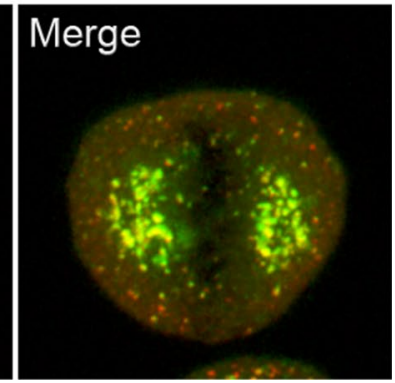

In conclusion, by the end of the 1980s both morphological and functional data were available supporting the existence of a distinct sorting compartment at the ER-Golgi boundary. Notably, the post-ER retrieval of KDEL-proteins meant that to support specific ligand-receptor interactions such a pre-Golgi compartment had to maintain its own luminal conditions and therefore be discontinuous with the ER (Pelham 1989). Indeed, subsequent studies showed that the binding of the KDEL-ligands to their receptor prefers a slightly acidic $\mathrm{pH}$ (Wilson et al. 1993), indicating that pre-Golgi protein sorting is dependent on luminal acidification, in analogy to the sorting events taking place in endosomes and trans-Golgi. Subsequently, a number of studies have highlighted the importance of luminal acidification in two-way trafficking and quality control within the IC (Appenzeller-Herzog and Hauri 2004; Bu et al. 1995; Satoh et al. 1996). The luminal pH of the IC/cis-Golgi has been estimated to be between 6.0 and 6.7 (Vavassori et al. 2013). In addition, there is some evidence for a $\mathrm{pH}$ gradient, since only IC elements in the central Golgi area label with DAMP, a marker for acidic compartments (Palokangas et al. 1998).

\section{Identification of p58/ERGIC-53/LMAN1}

An important turning point in the study of the IC was the identification of its first endogenous marker protein p58/ ERGIC-53. Rat p58 was discovered with the help of a polyclonal antibody prepared against a cis-Golgi membrane fraction from pancreatic acinar cells, corresponding to the site of the $16{ }^{\circ} \mathrm{C}$ transport block (Saraste et al. 1986, 1987). The human homolog ERGIC-53 (89\% identity) was identified in a screen of monoclonal antibodies generated against a Golgi fraction isolated from cultured epithelial cells (Schweitzer et al. 1988). The cytoplasmic tails of these non-glycosylated type I transmembrane proteins (Lahtinen et al. 1992, 1996; Schindler et al. 1993) are equipped with KKFF-signals, which by binding to COPII- and COPI-coats result in their cycling between the ER and IC/cis-Golgi (Kappeler et al. 1997; Tisdale et al. 1997). The recycling of p58/ERGIC-53 
is inhibited when cells are kept at $15{ }^{\circ} \mathrm{C}$ (Fig. 1), resulting in the pile-up of the protein in the same pre-Golgi structures where the VSV and SFV glycoproteins are arrested (Plutner et al. 1992; Saraste and Svensson 1991; Schweitzer et al. 1990), verifying that the $15^{\circ} \mathrm{C}$ block site is equivalent to the compartment defined by p58/ERGIC-53.

Sequence comparisons also revealed the identity of ERGIC-53 with a human mannose-binding protein MR60 (Arar et al. 1995). Accordingly, the luminal N-terminus of ERGIC-53 was shown to contain an L-type lectin domain that specifically binds high-mannose oligosaccharides in a calcium-dependent manner (Itin et al. 1996; Velloso et al. 2003; Zheng et al. 2013), hence the additional designation LMAN1 (lectin mannose-binding protein 1). Today, p58/ERGIC-53/LMAN1 is the best-characterized receptor for export of soluble glycoproteins from the ER
(Appenzeller-Herzog et al. 1999). It employs both oligomerization (formation of dimers and hexamers) and accessory proteins (e.g., MCFD2 or ERp44) during its interaction with specific cargo, such as serum coagulation factors (Nichols et al. 1998; Zheng et al. 2013) or monomeric IgMs (Anelli and Sitia 2008; Cortini and Sitia 2010). Release of cargo from the receptor takes place in the low $\mathrm{pH}$ and calcium conditions prevailing in the lumen of IC/cis-Golgi (AppenzellerHerzog et al. 2004).

Localization of p58/ERGIC-53/LMAN1 by immuno-EM gave new data on the ultrastructure of the IC. In addition to the cis-most Golgi cisterna and small vesicles and tubules, p58 was found in large pleiomorphic structures with endosome-like appearance (Horstman et al. 2002; Lahtinen et al. 1992; Saraste et al. 1987; Saraste and Svensson 1991; Ying et al. 2000; Fig. 3). The expansion of the latter most likely
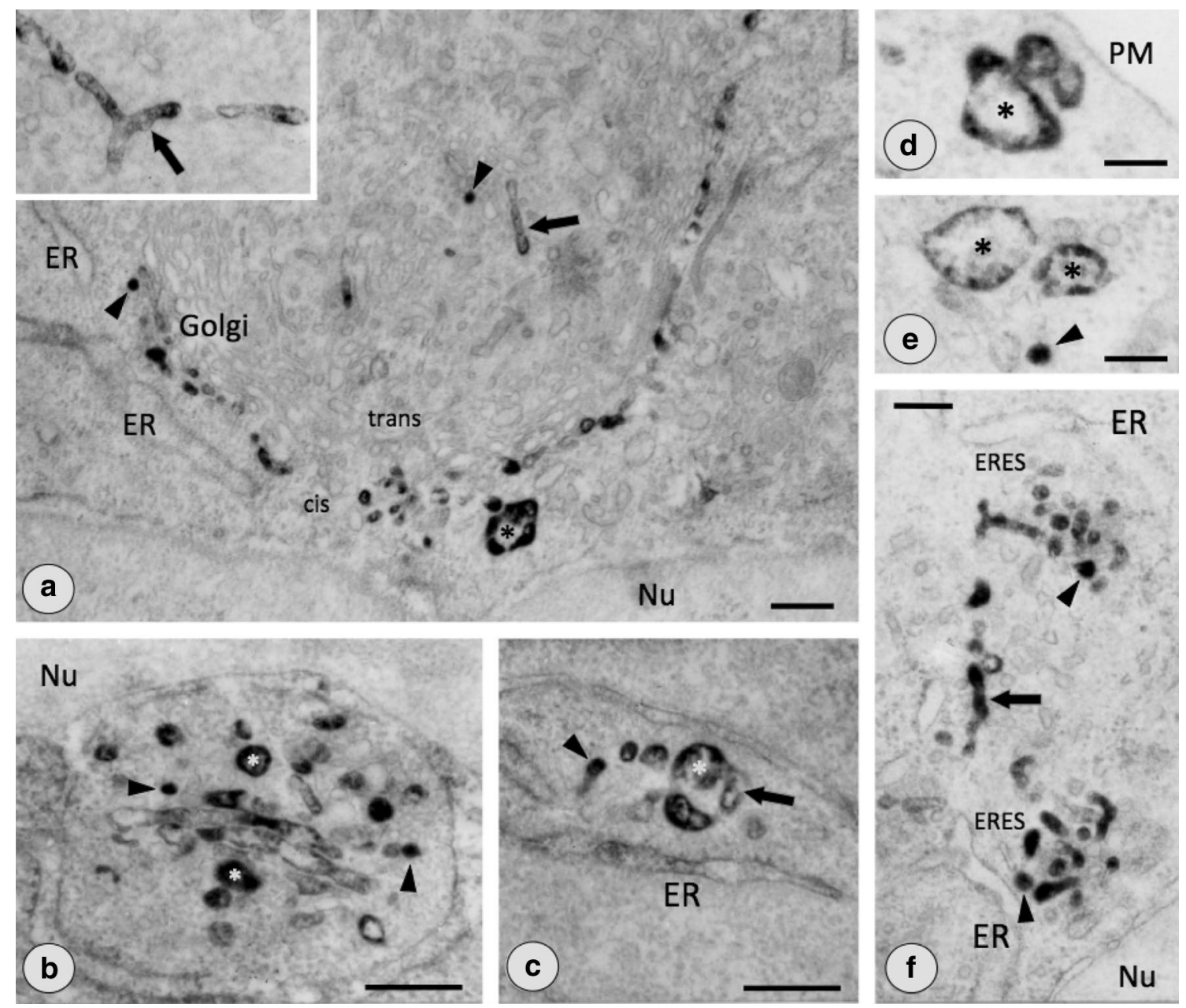

Fig. 3 Ultrastructure of the IC as examined by immunoperoxidase EM. The pleiomorphic nature of the p58-containing IC elements is illustrated by images taken of NRK (a) and mouse myeloma cells (b-f), showing the presence of this recycling receptor in the cismost Golgi cisterna, as well as small vesicles (arrowheads), narrow tubules (arrows) and large vacuolar structures (asterisks; diameter up to $0.5 \mu \mathrm{m})$. In addition to the cis-Golgi region, the latter are found throughout the cytoplasm, even close to the plasma membrane (PM). f p58-positive vesicular tubular clusters (VTCs) close to ER exit sites (ERES). ER, endoplasmic reticulum; $\mathrm{Nu}$, nucleus. Bars: $0.5 \mathrm{~mm}$ (a-c), $0.25 \mathrm{~mm}(\mathbf{d}-\mathbf{f})$. Reproduced from Saraste and Marie (2016) by permission from Elsevier. f Reproduced from Saraste et al. (1987) 
gives rise to the pre-Golgi vacuoles observed at $15{ }^{\circ} \mathrm{C}$ (Saraste and Kuismanen 1984; Trucco et al. 2004). However, other groups defined the IC as vesicular-tubular clusters (VTCs) that typically consist of small vesicles and tubules (see e.g., Fig. 3f), and are devoid of larger structures (Balch et al. 1994; Klumperman et al. 1998; Martínez-Menárguez et al. 1999). As discussed below, live imaging of IC dynamics indicates that the VTCs are stationary structures, while the vacuoles function as mobile cargo carriers within the IC system (Mironov et al. 2003). This could explain why many of the VTCs lack the large pleiomorphic IC component. Moreover, the existence of the latter is not only based on EM observations, but has been demonstrated by analytical differential centrifugation as well (Ying et al. 2000).

LM localization of p58 in different cell types confirmed the widespread distribution of the IC elements (Fig. 1; Saraste and Svensson 1991; see also; Lotti et al. 1992). Moreover, the striking disassembly of the Golgi stacks in cells treated with the newly introduced compound brefeldin A (BFA) was found to involve the formation long tubules, which mediate retrograde transport of Golgi enzymesevidently via the IC - to the ER (Lippincott-Schwartz et al. 1990). Together, these studies provided the first indication that two-way communication at the ER-Golgi boundary occurs over long distances and depends on the integrity of the cytoskeletal microtubule (MT) tracks. The observed spatial organization of the IC also meant that ER-to-Golgi transport and endocytosis share the same cellular topology. Accordingly, the two types of transport carriers, endosomes and "exosomes", were suggested to travel "side by side" from the periphery to the cell center and even communicate along the way (Saraste and Kuismanen 1992).

\section{Building IC domains: Rab1 and Arf1/COPI in action}

Starting with the pioneering studies in the early 1980s, applying yeast genetics and biochemical dissection of mammalian cell-free systems (Bonifacino and Glick 2004; Lee et al. 2004), a wealth of information has accumulated on the molecular machineries that regulate transport in the early secretory pathway-including cargo receptors, COP coats, Arf and Rab GTPases, tethering factors and fusion proteins. Recent comprehensive reviews have addressed the functions of these molecular players in more detail (Barlowe and Miller 2013; Gillingham and Munro 2016; Gomez-Navarro and Miller 2016; Hutagalung and Novick 2011; Kaczmarek et al. 2018; Malsam and Söllner 2011; Szul and Sztul 2011; Zanetti et al. 2012). Here, we focus on two components of this machinery, Rab1 and COPI coats, which appear to preferentially associate with different subdomains of the IC and play important roles in bi-directional ER-Golgi trafficking.

\section{Rab1-positive tubules}

GTPases of the Rab family-Ypt proteins in the yeast $S$. cerevisiae-are master regulators of membrane traffic. In their active membrane-bound conformation, they interact with multiple effectors, thereby affecting the assembly, motility, tethering or fusion of transport carriers. Moreover, by recruiting peripheral proteins and lipid-modifying enzymes to membranes, Rab proteins are thought to organize the formation of membrane domains, thereby having a major impact on organelle structure and identity (Behnia and Munro 2005; Stenmark 2009). The functions of the different compartment-specific Rab proteins acting in the secretory and endocytic pathways are coordinated by guanine nucleotide exchange factors (GEFs) and GTPase-activating proteins (GAPs) that regulate the switch between their active (GTPbound) and inactive (GDP-bound) states, thereby ensuring the directionality of transport. The three Rab proteins operating in the yeast secretory pathway, Ypt 1 (yeast counterpart of Rab1), Ypt31/32 (Rab11) and sec4 (Rab8), provide an example of such a Rab cascade (Lipatova et al. 2015; Mizuno-Yamasaki et al. 2012). Recent studies support the idea that both yeast and mammalian cells contain two conserved transport protein particle (TRAPP) complexes-TRAPPIII and TRAPPII-which can act as GEFs during the activation of Ypt1 (Rab1) and Ypt31/32 (Rab11) (Riedel et al. 2017; Thomas et al. 2018). However, although the successive functions of the TRAPPs in the yeast secretory pathway is relatively well established (Suda et al. 2018), the roles of their mammalian counterparts remain less clear. One complication is that yeast Ypt31/32 is considered a component of the trans-Golgi/TGN, whereas its mammalian ortholog Rab11 associates with the endocytic recycling compartment (ERC)—also referred to as recycling endosomes.

$\mathrm{Rab} 1 / \mathrm{Ypt} 1$ is the best-known Rab protein acting in the early secretory pathway (Goud et al. 2018; Lipatova et al. 2015; Saraste 2016). Mammalian Rab1 is an abundant GTPase (Gilchrist et al. 2006) that specifically associates with the cytoplasmic side of pre-Golgi membranes, being present throughout the IC network (Griffiths et al. 1994; Marie et al. 2012; Saraste et al. 1995; Satoh et al. 2003). Live imaging showed the striking oscillatory recruitment of GFP-Rab1 to IC elements, their subsequent movement from ERES either to the Golgi region or the cell periphery and the bi-directionality of both pathways (Sannerud et al. 2006). It also revealed the association of Rab1 with an extensive network of narrow tubules, which are in dynamic continuity with the "globular" (vacuolar) parts of the IC (Fig. 2, see below, Fig. 5). Notably, this tubular system expands during neuronal differentiation, suggesting its possible biosynthetic functions (Sannerud et al. 2006).

The preference of Rab1 for the tubular domain of the IC also resulted in the uncovering of the centrosomal 
connection of this compartment. Due to centrosome re-positioning in motile cells, or at the onset of mitosis (see below, Fig. 6), a pool of Rab1-positive membranes separates from the Golgi ribbon and forms a tubular meshwork at the cell center (Marie et al. 2009; Mochizuki et al. 2013; Figs. 1, 2). In migrating cells, this event may be required for the rapid delivery of components to the cell's leading edge, while the mitotic event most likely initiates the partitioning of the IC (Marie et al. 2012; Dale et al. in preparation). Due to its similarity with the pericentrosomal ERC, we designated this central domain of the IC as the biosynthetic recycling compartment (BRC; Saraste and Goud 2007). The localization of the KDEL-receptor to these membranes (Fig. 2) is in accordance with their key role in membrane recycling.

Many of the effectors of Rab1-such as p115, GM130 and giantin-function in membrane tethering, suggesting its participation in multiple transport steps (Goud et al. 2018; Saraste 2016). Accordingly, like yeast Ypt1, Rab1 regulates bi-directional ER-Golgi trafficking (Galea et al. 2015; Kamena et al. 2008; Plutner et al. 1991), in agreement with the presence of both antero- and retrograde cargo in IC tubules (Palokangas et al. 1998; Simpson et al. 2005). In addition, Rab1 has been implicated in intra-Golgi traffic (Plutner et al. 1991), although this function may not be readily compatible with its reported localization to the IC/cisGolgi. Rab1 also plays an important in role Golgi biogenesis (Haas et al. 2007; Goud et al. 2018). Knockdown of Rab1 leads to Golgi fragmentation (Aizawa and Fukuda 2015; Galea et al. 2015), while microinjection of Rab1 mutants causes complete Golgi disassembly (Wilson et al. 1994). As discussed below, Rab1 (or one of its two isoforms) may also regulate pathways that bypass the Golgi stacks.

\section{COPI-coated vacuoles}

Like Rab1, COPI coats preferentially associate with the IC/cis-Golgi (Griffiths et al. 1995; Oprins et al. 1993; Orci et al. 1997). For example, in professional secretory cells about $70 \%$ of the coats associate with the pre-Golgi VTCs (Martínez-Menárguez et al. 1999). In addition, COPI is involved in vesicle formation at the lateral rims of the Golgi stacks (Duden et al. 1991; Rabouille and Klumperman 2005). The binding of COPI coats to membranes is regulated by GTPases of the Arf family. Interestingly, Arf1-the master COPI regulator at the IC/cis-Golgi-is also involved in the recruitment of clathrin adaptor proteins (APs) at the trans-Golgi/TGN (Kaczmarek et al. 2018). The GEFs activating Arf1 at the cis- and trans-sides of the Golgi-GBF1 and BIG1/BIG2, respectively-are the targets for BFA (Mansour et al. 1999; Togawa et al. 1999). Besides Arf1, also Arf4 and Arf5 have been implicated in ER-Golgi trafficking (Ben-Tekaya et al. 2010; Chun et al. 2008; Volpicelli-Daley et al. 2005), suggesting the operation of different types of COPI vesicles (Popoff et al. 2011) at the level of the IC. In line with this possibility, the pericentrosomal BRC that separates from the Golgi ribbon contains a distinct pool of COPI coats (Marie et al. 2009).

As mentioned earlier, the general idea is that the COPI vesicles mainly function in retrograde transport (Rabouille and Klumperman 2005). Interestingly, however, blocking GBF1 function-by knock-down or using the specific inhibitor Golgicide A-arrests the VSV G-protein in the IC, suggesting a role of COPI coats in anterograde IC-to-Golgi transport (Manolea et al. 2008; Sáenz et al. 2009). Also, recent studies demonstrated the involvement of COPI-coated tubules in anterograde transport of VSV G protein at the level of the Golgi stacks (Park et al. 2015; Yang et al. 2011). Furthermore, besides generating vesicles, COPI coats could contribute to the organization of the IC elements (Bonifacino and Lippincott-Schwartz 2003). In this respect it is of interest that they seem to preferentially associate with the vacuolar IC domains (Horstmann et al. 2002; Presley et al. 2002; Sannerud et al. 2006; see below).

In conclusion, Rab1 and Arf1/COPI could play important roles in the formation of vacuolar and tubular IC domains, which play distinct roles in trafficking. The dynamic continuity of these subdomains (see below) suggests that their formation and functions are highly co-ordinated. Accordingly, Rab1 has been reported to participate in COPI-dependent vesicular (or tubular) transport (Alvarez et al. 2003; Gilchrist et al. 2006; Monetta et al. 2007), and inhibition of COPI function typically results in the proliferation of the tubular IC domain (Ben-Tekaya et al. 2010; Marie et al. 2009; Szul et al. 2007). Obviously, this is a simplistic scenario and future studies are expected to reveal a number of additional factors, such as lipid-modifying enzymes (Bechler et al. 2011; Ben-Tekaya et al. 2010), which greatly impact IC organization. In addition, cytoskeletal filaments are required for the remodeling of the IC elements, as highlighted by recent studies of WHAMM, an activator of actin nucleation, which is recruited to IC tubules by Rab1 and also interacts with MTs. (Campellone et al. 2008; Russo et al. 2016).

Finally, the preferential pre-Golgi localization of Rab1 and COPI in mammalian cells emphasize the compositional and functional similarity of the IC with the Ypt1-containing cis-Golgi compartment in the yeast $S$. cerevisiae. Taking into account that Rab proteins define organelle identity, it is of interest that Rab1 can functionally replace Ypt1 in yeast (Haubruck et al. 1989). In addition, COPI coats turn out to play analogous roles in the two compartments by ensuring membrane recycling and organelle maturation (Papanikou et al. 2015). 


\section{Modeling the IC}

The static images generated by the early EM studies, employing transported cargo or the newly identified resident proteins as IC markers (see, e.g., Fig. 3), left ample room for interpretation and opened up for different ideas on the nature of this compartment. For example, the IC was considered a subdomain of the ER (Krijnse-Locker et al. 1994; Sitia and Meldolesi 1992) or part of a cisGolgi network (CGN), a tubular compartment analogous to the TGN operating in membrane recycling at the entry face of the Golgi stacks (Mellman and Simons 1992). The CGN concept rapidly gained popularity, probably explaining why it took some time-close to 20 years-before the IC became more generally accepted as a distinct pre-Golgi structure, as evidenced by its entry into the textbooks (Alberts et al. 2002). This development was due to the introduction of new methodology, allowing, e.g., the coupling of the synchronizable VSV tsO45 G-protein with green fluorescent protein (GFP) to visualize pre-Golgi membrane dynamics in living cells (Presley et al. 1997; Scales et al. 1997). These pioneering studies revealed the translocation of large pre-Golgi structures (up to $1 \mu \mathrm{m}$ in diameter) along MT tracks, mediating long-distance transfer of cargo between peripheral ER sites and the central Golgi apparatus. They also demonstrated in vivo the division of these structures into globular (vacuolar) and tubular subdomains (Presley et al. 1998, see below). Subsequently, a number of fluorescent reporters have been used to visualize ER-to-Golgi transport (Verissimo and Pepperkok 2013). However, despite all the efforts, the nature of the IC remains a matter of dispute. The various fluorescent markers employed may highlight different aspects of IC dynamics due to their differential enrichment in the two IC subdomains. In addition, some may not faithfully recapitulate the behavior of their endogenous counterparts. Nevertheless, live imaging has provided the basis for three different models of the IC, as discussed in the following.

\section{Model A: transient transport carriers}

The currently prevailing model-and accordingly the one presented in many textbooks - views the pleiomorphic IC elements as transient cargo carriers (Fig. 4a). This model has its roots in the early studies on the dynamic pre-Golgi elements containing membrane-bound or soluble cargo, such as VSV G-protein or procollagen (Presley et al. 1997; Scales et al. 1997; Shima et al. 1999). In this model the IC elements are first assembled at ERES in process that involves the homotypic fusion of ER-derived COPII vesicles. They then move in a saltatory ("stop-and-go") fashion to the Golgi region where they appear to merge with the Golgi stacks. In essence, the IC elements are transient structures that are continuously made de novo at ERES and consumed at cis-Golgi.

Since this model presents the pre-Golgi elements as cargo carriers themselves, they have also been referred to as transport complexes (TCs; Bannykh and Balch 1997; Stephens and Pepperkok 2001). Indeed, the well-documented size and shape heterogeneity of the vacuolar, tubular and vesicular IC elements (Fig. 3; Ying et al. 2000) opens up for their function as different types of carriers- "cars and trucks" (Fan et al. 2003) —with the ability to accommodate different types of large or small cargo, such as procollagen fibers, lipoprotein particles, soluble or membrane-bound proteins or lipids. Interestingly, carrier formation at ERES for largesized cargo turns out to involve a highly complex interplay between the COPII machinery, IC membranes, and novel organizers, such as TGF and TANGO (Hanna et al. 2018).

It should be noted that the TC model is based on the assumption that the mobile pre-Golgi carriers that can be resolved by LM correspond to the large-sized VTCs. However, a number of studies have documented that these elements become elongated as they start to move (Marie et al. 2009; Presley et al. 1997, 2002; Sannerud et al. 2006). Since the VTCs are unlikely to be capable of such a shape change, it may be important to make a distinction between stationary VTCs residing at ERES and large vacuolar IC elements that are deformable for transport purposes (Lippincott-Schwartz et al. 1998; Fig. 3).

The long distance saltatory movements of the IC elements from ERES to the cell center-at a speed of about $1 \mu \mathrm{m} / \mathrm{s}$ take place on the MTs radiating from the centrosome (Gurel et al. 2014). This centralization process depends on the minus-end directed MT motor dynein that associates with the IC membranes (Burkhardt et al. 1997; Presley et al. 1997; Roghi and Allan 1999; Watson et al. 2004). A good candidate for the receptor that links dynein to IC elements is the Arf1 effector golgin-160, a long coiled-coil tethering protein that localizes to the cis- and lateral sides of the Golgi stacks. Namely, besides recruiting dynein to central Golgi elements, golgin-160 is also required for anterograde ER-to-Golgi transport (Yadav et al. 2012). Moreover, its dissociation from membranes during mitosis coincides with inhibition of the centralization of IC elements that still interact with spindle MTs (Marie et al. 2012; Yadav et al. 2012). Notably, the IC also contains the plus-end directed motor kinesin (Lippincott-Schwartz et al. 1995; Tomás et al. 2010), which could be involved in retrograde transport, the shaping of the vacuolar and tubular elements or their positioning at ERES and/or Golgi region (Brown et al. 2014). A special class of MTs that are nucleated at cis-Golgi membranes (Rivero et al. 2009) has been implicated in the formation of the Golgi ribbon. Whether these non-centrosomal MTs have additional roles in ER-Golgi trafficking remains unknown. 

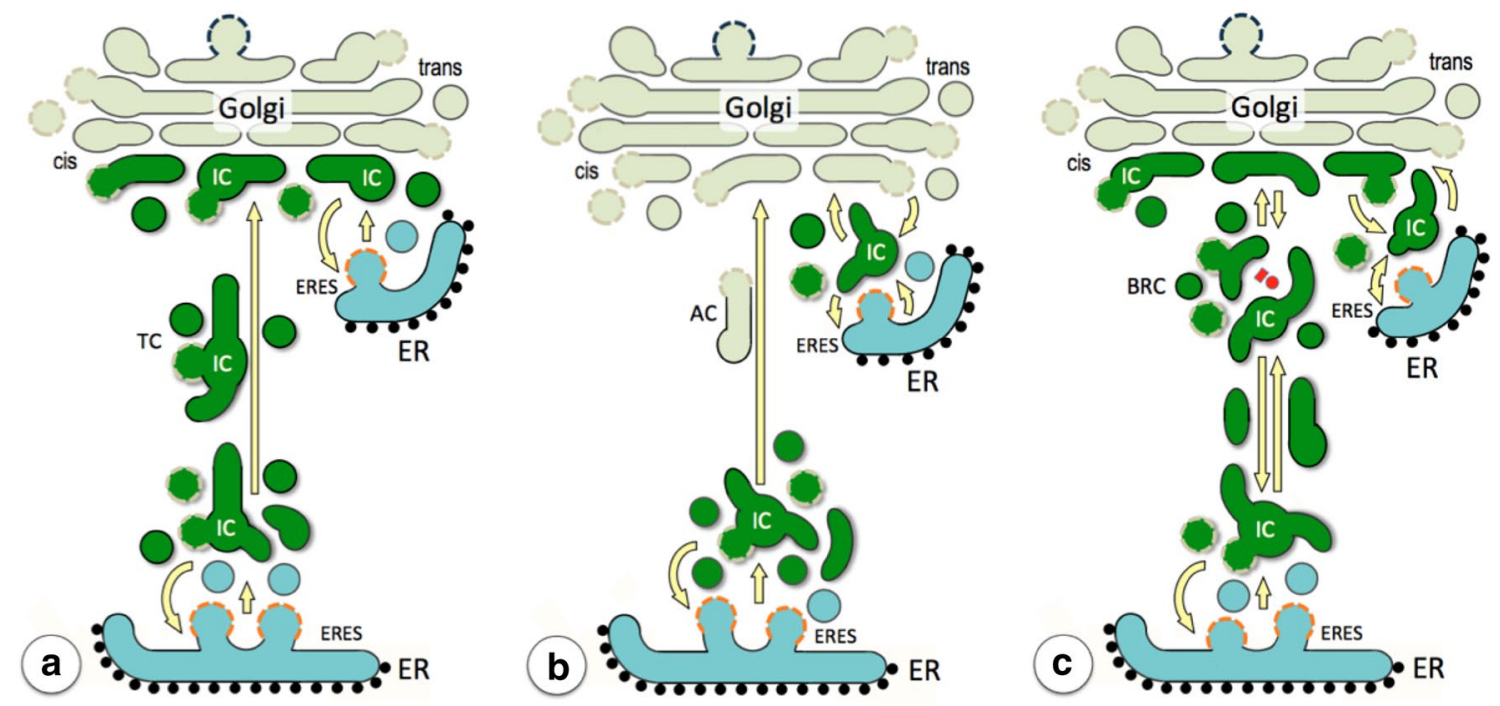

Fig. 4 Different views of the IC in mammalian cells. All three models depict the existence of peripheral and central, Golgi-adjacent ERES. They focus on the role of the IC in ER-Golgi trafficking and do not illustrate "lateral" communication between the IC elements residing next to ERES. a The IC elements act as transport carriers. According to this model the IC consists of vesicular tubular clusters (VTCs) that form de novo at ERES via homotypic fusion of COPII vesicles (orange coats). The VTCs are mobilized in bulk and move in a MTdependent stop-and-go fashion-most likely from ERES to ERESto the cis-Golgi region. These mobile transport carriers (TCs) can change their composition by budding COPI vesicles (gray coats). Depending on whether the Golgi stacks are stationary or maturing structures, the TCs either fuse with or transform into cis-Golgi cisternae (as shown here). The latter event would involve homotypic fusion between the IC elements. b A stable IC residing next to ERES. Here the IC is thought to consist of ERES-associated, long-lived membrane clusters that are relatively immobile and maintain bi-directional communication with the ER and cis-Golgi. Accordingly, ER-to-Golgi transport requires two heterotypic fusion events. The first involves the fusion of COPII vesicles with pre-existing IC elements, and the second the delivery of newly synthesized cargo to the cis-Golgi by IC-derived anterograde carriers (ACs). c A permanent network of

\section{Model B: stationary ERES-associated membrane clusters}

Live imaging of GFP-coupled ERGIC-53 in HeLa cells showed its preferential localization to long-lived stationary structures, providing a basis for an alternative model of the IC (Ben-Tekaya et al. 2005). According to this model, the IC is a stable compartment consisting of a constant number of tubulovesicular clusters (VTCs) that reside in the vicinity of the widely distributed ERES (Klumperman et al. 1998). These clusters communicate with the ER and cis-Golgi with the help of distinct transport carriers (AppenzellerHerzog and Hauri 2006). Accordingly, ER-derived COPII vesicles first undergo heterotypic fusion with the stable IC elements, whereafter the latter generate a second class of anterograde carriers (ACs) that separate from the stationary dynamic IC elements. This model combines key aspects of the previous models by considering that two types of IC componentsvacuoles and tubules, which display distinct dynamics-mediate long-distance communication within a permanent IC network. Thus, relatively stationary vacuoles anchored at ERES are interconnected with other peripheral (not shown) or central vacuoles via dynamic tubules. Due to this MT-dependent communication, vesicle-mediated exchange of material with the ER and the recruitment of proteins from the cytosol, the vacuoles mature, become mobile, change shape and move along MT tracks between neighboring ERES (not shown), as well as between peripheral ERES and the Golgi region. The vacuoles arriving at the cell center are anchored at the non-compact regions that connect the Golgi stacks (see Fig. 7). Thus, these membranes are normally distributed at multiple sites across the Golgi ribbon, but, due to their MT-dependent connection with the centrosome (red), can also establish an extensive compartment (BRC), as the latter separates from the Golgi ribbon (as shown here). Communication within this IC network, including the events taking place at cis-Golgi, is expected to involve homotypic fusions between vacuolar, tubular and vesicular IC elements. Adapted from Saraste and Marie (2016). By permission from Elsevier

IC clusters and move along MT tracks to the cis-Golgi (Fig. 4b). Surprisingly, while GFP-ERGIC-53 was detected in mobile tubules that "laterally" connect the IC clusters (Ben-Tekaya et al. 2010), it was absent from the Golgidirected ACs, despite the fact that the endogenous p58/ ERGIC-53 can reach the cis-Golgi cisternae (Schweitzer et al. 1988; Klumperman et al. 1998; Fig. 3). However, the ACs contained a soluble reporter (signal sequence-containing DsRed; Ben-Tekaya et al. 2005), suggesting that they represent authentic cargo carriers.

The stable IC model received support from studies on a neuronal GABA transporter, indicating that the protein contains a special motif required for its exit from the IC (Farhan et al. 2008). Furthermore, previous observations on the presence of COPI coats on motile pre-Golgi carriers (Presley et al. 2002; Scales et al. 1997; Shima et al. 1999) 
lead to the proposal that these coats organize the formation of the novel ACs (Appenzeller-Herzog and Hauri 2006). In this respect, the stable IC model is also in accordance with previous ideas on the dual function of COPI in antero- and retrograde trafficking at the level of the IC (Lowe and Kreis 1998). It is also supported by the early results concerning the effect of BFA on the localization of p58/ERGIC-53. Namely, upon COPI removal by BFA Golgi proteins redistribute to the ER, whereas p58/ERGIC-53 remains associated with apparently stable IC structures at ERES (Fullekrug et al. 1997; Lippincott-Schwartz et al. 1990; Saraste and Svensson 1991; Ward et al. 2001).

\section{Model C: permanent network of dynamic vacuoles and tubules}

The most recent model of the IC elaborated here (Fig. 4c) based on live imaging of GFP-Rab1 dynamics in NRK cells (Marie et al. 2009, 2012; Sannerud et al. 2006; Saraste and Marie 2016) — combines the dynamic and stationary aspects of the two previous models. It retains the idea that the IC elements themselves function as mobile transport carriers (Model A). However, instead of moving from ERES to cisGolgi these vacuolar and tubular carriers, which display distinct dynamics, are suggested to operate in the context of an interconnected IC network. Thus, despite being highly dynamic, the IC is considered as a permanent organelle. An advantage of this model is that it can take into account both the extensive evidence of the dynamics of the IC elements and recent data that speaks in favor of their stability.

As discussed above, Rab1 binds to the cytoplasmic side of the vacuolar and tubular IC elements, with some preference for the tubular domain. Previously, the two endogenous IC markers Rab1 and p58/ERGIC-53 were shown to display overlapping intracellular distributions (Sannerud et al. 2003; Saraste et al. 1995; Fig. 2). Accordingly, fluorescent GFPRab1 was found to associate with two types of elements in living cells, evidently corresponding to those highlighted also by GFP-ERGIC-53. Firstly, it bound to large ERESassociated structures that remain stationary for variable periods of time. However, most of them eventually become mobile, change shape-become elongated-and move toward the Golgi region or the cell periphery (Marie et al. 2009; Sannerud et al. 2006). As pointed out earlier, by being deformable they must correspond to vacuoles rather than VTCs. Second, GFP-Rab1 was localized to highly dynamic long tubules that protrude from the vacuoles, pinch off andjust like the vacuoles-display bi-directional mobility along MTs, moving either to the Golgi region, or in the opposite direction, toward the cell periphery (Fig. 5). Despite the direction, the vacuolar and tubular dynamics takes place in a stop-and-go fashion, i.e., from ERES to ERES. An interesting additional feature revealed by GFP-Rab1 imaging was bolus structures, that is, vacuolar structures that develop a long tubule and then appear to slide along it (Marie et al. 2009; Fig. 5). Similar mobile boluses have been previously described in the endosomal system (Ayala 1994; Hopkins et al. 1990).

The separation of the BRC from the Golgi ribbon (Fig. 6a) allowed the identification of the entry sites of the IC elements arriving at the cell center from peripheral ERES. Namely, instead of moving directly to cis-Golgi, these mobile vacuoles and tubules are targeted to the pericentrosomal BRC (Fig. 5). Furthermore, imaging of IC dynamics in BFA-treated cells-following the disassembly of the Golgi stacks-revealed ongoing communication between the peripheral ERES and the BRC, which persists in these cells (Marie et al. 2009) and maintains its connection with the ERC. These results confirmed that the dynamic IC network, besides docking at ERES, is also anchored at the cell center due to its connection with the centrosome and the endocytic recycling system. Moreover, imaging of GFP-Rab1 dynamics in motile NRK cells, showing bi-directional movements of IC vacuoles and tubules between peripheral ERES and the cell's leading edge (Sannerud et al. 2006), provided evidence that the IC is also anchored at the cell periphery. Evidently, a widespread dynamic membrane system, like the IC, could become permanent due to its anchoring at the peripheral and central end stations of the cytoskeletal MT tracks that allow bi-directional motility of its two types of constituentsrelatively stationary vacuoles and highly dynamic tubules, which bud off and fuse with the vacuoles.

The idea of a stable IC received strong support from studies of mitotic cells. As cells enter mitosis, ER exit is blocked and the Golgi apparatus undergoes reversible disassembly. By contrast, the Rab1-containing IC elements persist, maintaining their compositional properties and association with the MT-based mitotic spindle. Accordingly, they are present both at the cell periphery and around the centrosomes at the spindle poles (Fig. 2). Interestingly, at mitotic prophase the BRC expands and divides in a process that is coupled to the re-positioning of the centrosomes and their movement to the spindle poles (Fig. 6). Thus, by demonstrating its autonomy from the ER and Golgi, as well as its special inheritance strategy, the IC is likely to constitute a permanent membrane system with self-organizing capability (Marie et al. 2012).

\section{Comparing the models}

Regarding Models B and C (Fig. 4), although the dynamic features of the IC revealed by the two reporters GFPERGIC-53 or GFP-Rab1 were otherwise very similar, a major difference was the distinct mobilities of the large IC elements. One possible answer to this puzzle could be that GFP-Rab1 associates with the ACs that detach from the 
Fig. 5 Dynamics of the IC network as studied by spinning disk confocal microscopy. The images are derived from a movie taken from a GFP-Rab1expressing NRK cell displaying a BRC (asterisk), which has separated from the Golgi ribbon. The time projection highlights three types of tracks related to the MT-dependent movements of the IC elements between (i) peripheral ERES, (ii) peripheral ERES and the $\mathrm{BRC}$, and (iii) the BRC and the Golgi ribbon. Selected images (time $=$ seconds) corresponding to the framed area, showing the motility of both globular (vacuolar) and tubular IC elements. A globular structure (white arrowhead) continuously sheds narrow tubules (open arrowheads), while it itself also moves in a stop-and-go fashion toward the cell center BRC (asterisk). These events also appear to involve its movement as a varicosity (bolus) along the tubule it first extends. Bars: $10 \mu \mathrm{m}$ (upper panels), $2 \mu \mathrm{m}$ (bottom panels). Adapted from Marie et al. (2009)
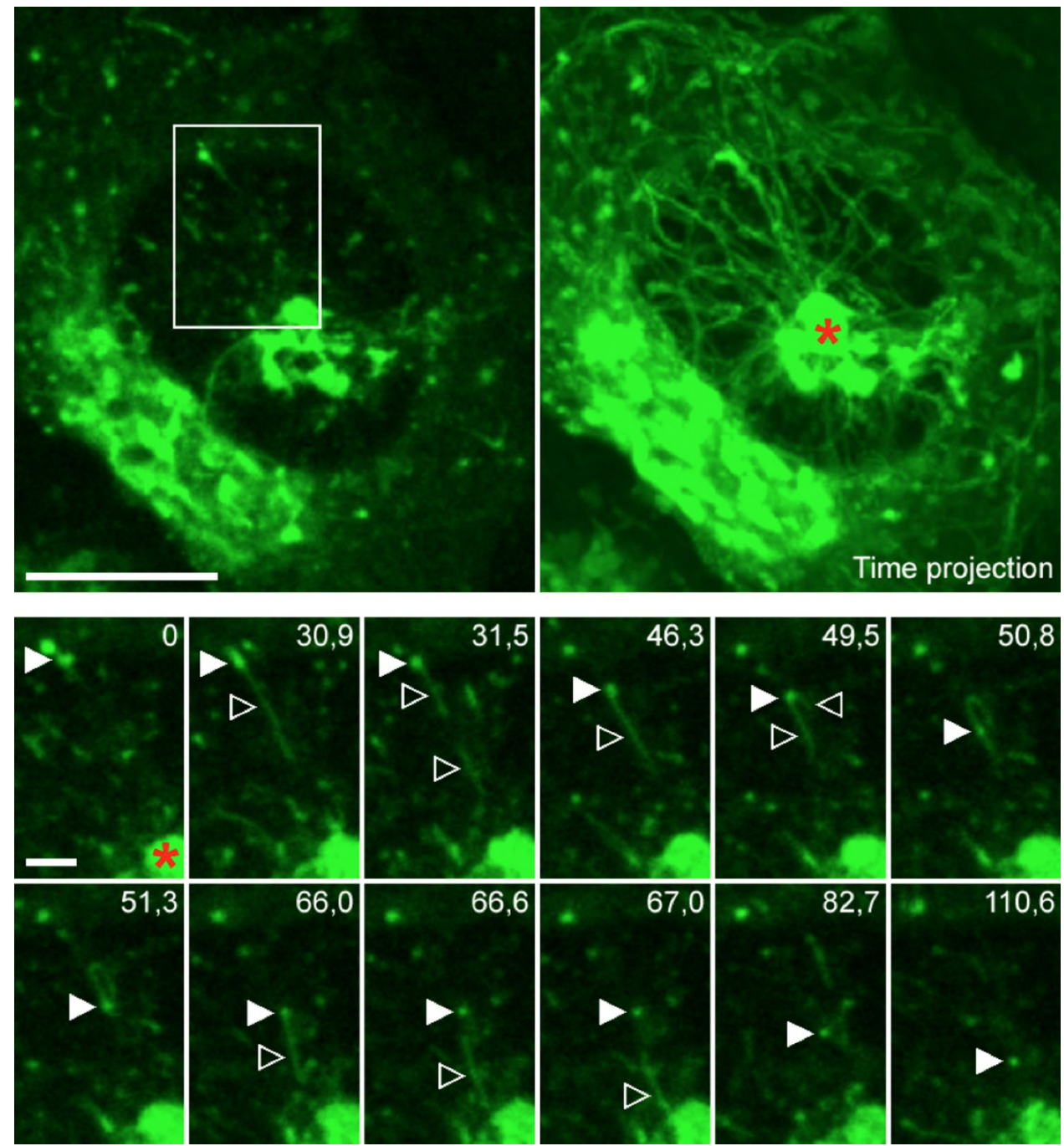

stationary IC clusters proposed in Model B. However, the notion that Rab1 is recruited to the ERES-associated IC elements in an oscillatory and BFA-resistant fashion (Sannerud et al. 2006; Marie et al. 2009), and does so to facilitate their fusion with COPII vesicles (Allan et al. 2000), makes this scenario unlikely. Another possibility is that the expression and mis-sorting of GFP-ERGIC-53 affects the maturation of the IC elements and/or their ability to gain transport competence-for example, by interfering with motor recruitment. It is also worth noting that, besides membrane-bound and soluble cargo (VSV-G and procollagen), a variety of other fluorescent reporters-including VIP36, which is closely related to p58/ERGIC-53/LMAN1 - have demonstrated the mobility of the large IC elements (Blum et al. 1999; Chao et al. 1999; Dahm et al. 2001; Monetta et al. 2007).

The two models proposing the function of the IC elements as mobile transport carriers (Models A and C) are compatible with their proposed maturation, in contrast to Model B depicting a stationary IC. As discussed above, extensive membrane recycling is expected to result in the creation of compositional differences between the peripheral and central IC elements. In analogy to endosomes, the luminal conditions of the IC elements could gradually change, resulting in the establishment of a pH gradient (Palokangas et al. 1998). Acidification could also depend on the connection of the IC elements and endosomes, a possibility incorporated in Model C (see below), and affect their function in protein sorting, for example, via the recruitment of special types of COPI coats (Aniento et al. 1996). In addition, maturation via membrane recycling has been proposed to lead to the concentration of secretory proteins in the lumen of the IC elements (Martínez-Menárguez et al. 1999; Oprins et al. 2001). According to the "dynamic IC models" (Models A and C), the formation of containers for soluble cargo follows simple one-step logistics, while the "stationary IC model" (Model B) suggests a more complicated process.

Obviously, the three IC models propose very different landscapes for the transport machineries operating at the ER-Golgi interface. Regarding COPI vesicles, Model A emphasizes their prominent role in retrograde transport to 

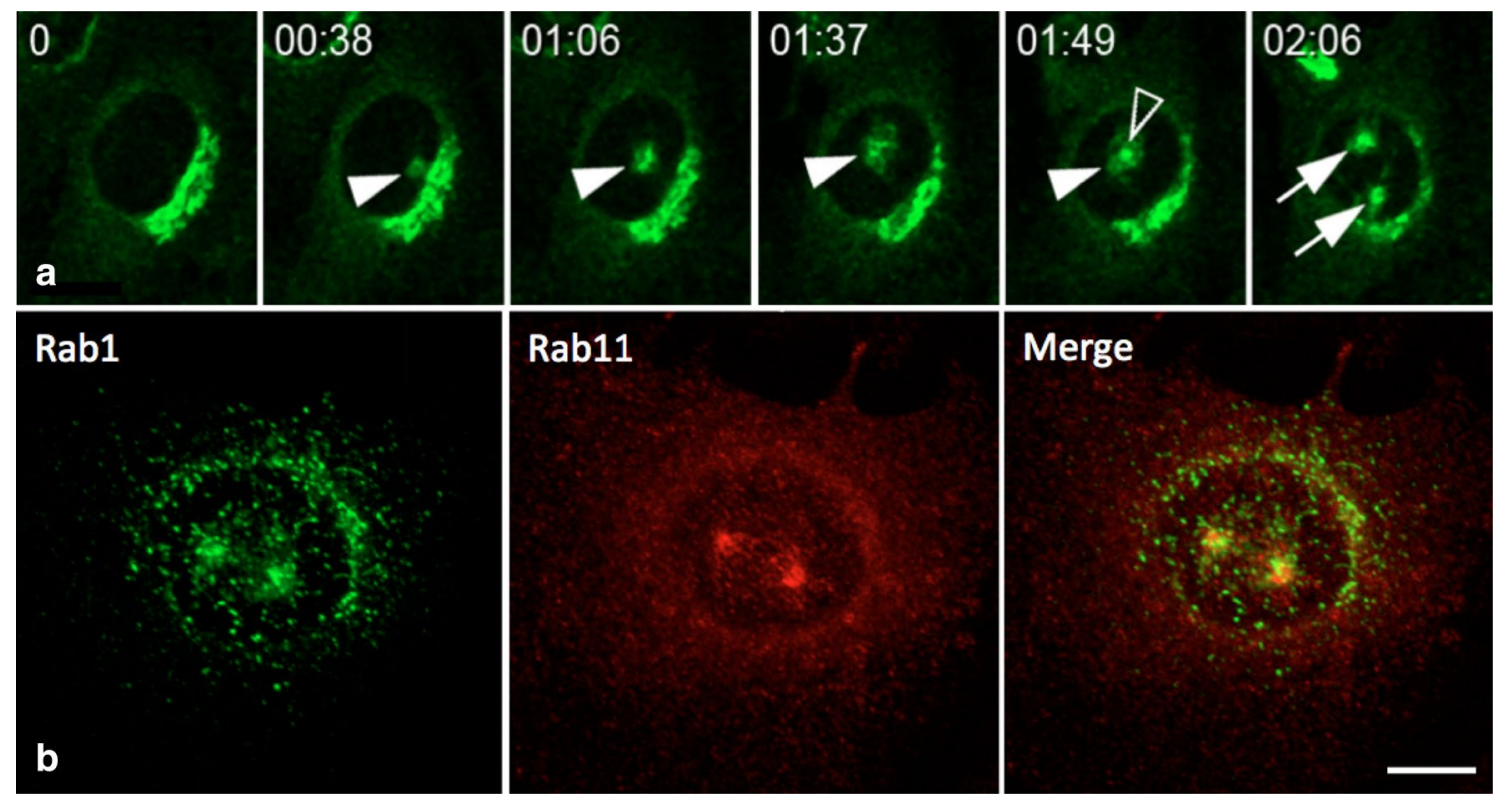

Fig. 6 Simultaneous division of the Rab1- and Rab11-containing pericentrosomal compartments, BRC and ERC, at the onset of mitosis. a Selected images from a time-lapse movie (time h:min) showing an NRK cell expressing GFP-Rab1 and progressing from interphase $\left(\mathrm{G}_{2}\right)$ to mitosis. The BRC (white arrowheads) separates from the Golgi ribbon, undergoes first expansion and then compaction

the ER, while the two "stable IC models" (Models B and C) open up for an additional anterograde function, a view that has been revitalized by recent studies (Park et al. 2015). Alternatively, COPI coats could function in the formation of the ACs from the stationary IC clusters (Model B; Appenzeller-Herzog and Hauri 2006), or in anterograde transport from the central IC elements to $\mathrm{cis}$-Golgi (Model C). Supporting the latter possibility, the BRC contains a separate pool of COPI (Marie et al. 2009). Model C also suggests a possible additional function of COPI vesicles in retrograde trafficking within the permanent IC network; namely, while both p58/ERGIC-53 and KDEL-R employ COPI vesicles in their trafficking, their recycling itineraries differ. Thus, during mitosis, due to the establishment of ER exit block, p58 is arrested in the ER, while KDEL-R remains as an IC component (Marie et al. 2012; Fig. 2b).

Regarding other transport factors, the two IC-associated Rab proteins, Rab1, Rab2, and their effector proteins, many of which function in membrane tethering, have been discussed elsewhere (Saraste 2016). Generally, the IC localization of the latter-for example, GM130 (Fig. 1; see also Marra et al. 2007)—opens up for their participation in homotypic fusion events within the permanent IC network, or in transport between central IC elements and the Golgi stacks (Model C).

Finally, the three models present quite different views on the relationship between the IC and the cis-Golgi (open arrowhead), and finally divides at prophase (arrows), based on the movement of the centrosomes to form the spindle poles. b Double staining of a GFP-Rab1-expressing NRK cell undergoing prophase with antibodies against Rab11 reveals joint division of the BRC and ERC. Reproduced from Marie et al. (2012). Bar: $10 \mu \mathrm{m}$

compartment (Fig. 4). In Model B, the peripheral stationary IC clusters and the cis-Golgi cisternae are considered as distinct entities. By contrast, Models $A$ and $C$ both assume a close biogenetic relationship between the two compartments, and thus are compatible with the notion that IC residents are typically also found in the cis-most Golgi cisterna. However, these models depict the connection between IC and cis-Golgi in different ways: In Model A transient IC elements generate cis-Golgi morphology in a maturation process, while Model C raises the possibility that the cis-Golgi is an extension of the permanent IC network.

\section{Novel functions of the IC}

Most of the well-characterized IC proteins are components of the transport machinery, supporting the view that the major-if not the only-task of this compartment is to carry out protein sorting and trafficking. However, over the years the IC has been assigned a variety of biosynthetic functions, such as protein folding and quality control, initiation of O-glycosylation, modification of N-linked high-mannose oligosaccharides and synthesis of glycosaminoglycans and lipids (Alvarez et al. 1999; Breuza et al. 2004; Jönsson et al. 2003; Krijnse-Locker et al. 1994; Sannerud et al. 2006; Sirkis et al. 2017; Tooze et al. 1988), indicating that its biosynthetic activities could have been 
underappreciated. Notably, recent studies have revealed the participation of the IC in cellular events that are not directly related to ER-Golgi trafficking. Moreover, since some of these novel tasks suggest complex interactions with the endosomal system, they are better suited for a permanent than a transient compartment.

\section{Golgi bypass}

The intimate connection between the centrosome-linked tubular networks, BRC and ERC, is maintained not only in BFA-treated cells (Marie et al. 2009), but also during the different phases of mitosis, when the Golgi is disassembled in a controlled and reversible manner (Marie et al. 2012; Szigetvari et al. unpublished results; see Fig. 6b). Notably, various lipids and membrane proteins-including cholesterol, adhesion proteins, ion channels and GPI-anchored proteins-are delivered to the cell surface in the presence of BFA (Baldwin and Ostergaard 2002; Gee et al. 2011; Martin et al. 2001; Schotman et al. 2008; Tveit et al. 2009; Urbani and Simoni 1990), raising the possibility that they employ a direct IC-to-recycling endosome route during their Golgi-independent trafficking (Marie et al. 2008; Prydz et al. 2013). Indeed, in accordance with the suggested role of an endosomal intermediate in unconventional trafficking of the cystic fibrosis transmembrane conductance regulator (CFTR), a chloride channel (Yoo et al. 2002), evidence was obtained that this protein passes through the pericentrosomal compartments on its way to the PM (Marie et al. 2009). Conversely, the stable IC-endosome link could explain how certain molecules entering the endosomal system from the PM, such as bacterial toxins (Sandvig et al. 1992), can gain access to the early compartments of the secretory pathway.

Recently, the idea of a Golgi bypass based on direct communication between the IC and the endocytic recycling system received strong support from an unexpected source, namely, the study of protein trafficking in neuronal dendrites. Remarkably, hundreds of transmembrane proteins of the synaptic PM-including neurotransmitter receptors, ion channels and adhesion proteins-that are locally synthesized at the neuronal periphery can reach the cell surface containing high-mannose oligosaccharides, indicating that they are not modified by Golgi enzymes. Moreover, cell surface expression of these proteins is not affected by BFA (Hanus et al. 2016). Furthermore, it turns out that most dendrites lack the so-called Golgi outposts, but do contain IC elements and recycling endosomes (Hanus et al. 2014; Krijnse-Locker et al. 1995; Sannerud et al. 2006). Thus, proteins leaving the dendritic ER are delivered to the surface of synaptic spines via a bypass route that connects these two compartments (Bowen et al. 2017). An important implication of these results is that similar "IC-recycling endosome units"- that may be more readily identifiable at the neuronal periphery-also exist in the densely packed perinuclear endomembrane system in the cell bodies. Evidently, Golgi bypass is not an exception to the rule-limited to a set of unconventional molecules-but an important general mechanism for polarized cell surface transfer of proteins and lipids (Prydz et al. 2008; Saraste et al. 2009) —at least in certain cell types and physiological situations.

The mechanism(s) of molecular exchange between the biosynthetic (IC) and endosomal networks remains an open question. Since Rab1 and Rab11 define these compartments (Saraste and Goud 2007), they are good candidates to regulate these transfers, as well. Indeed, many of the effectors of the IC-associated GTPases Rab1 and Rab2-such as GMAP210, p115 and GM130 (Fig. 1) —act in membrane tethering and also localize to the BRC (Roboti et al. 2015; Saraste 2016). Classical mechanisms involving COPI or clathrin coats are probably excluded, since the transfer is not affected by BFA. However, EM analysis revealed that the pericentrosomal tubules contain BFA-resistant coats (Tooze and Hollinshead 1992). Interestingly, many of the proteins displaying BFA-resistant trafficking have been implicated as components of lipid rafts (Marie et al. 2008), suggesting that IC-endosome communication may be based on lipidmediated sorting and trafficking (Zurzolo and Simons 2015). Also, the two types of tubules could establish membrane contact sites for the exchange lipids.

\section{Autophagosome biogenesis}

Interestingly, evidence for Rab1- and Rab11-dependent communication between the IC and recycling endosomes was provided by studies of autophagy. The formation of autophagosomes that sequester cytoplasmic material for degradation in lysosomes involves multiple organelles and depends on membrane traffic. Interestingly, recent studies have uncovered the important roles of the IC and recycling endosomes in this multistep process. Cell-free reconstitution revealed that the IC is an important membrane source for autophagosome formation (Ge et al. 2013). Surprisingly, both COPII and COPI vesicles have been suggested to deliver membrane from the IC/cis-Golgi to the forming autophagosome during the different stages of its assembly (Ge et al. 2017; Karanasios et al. 2016). In addition, Rab1 and Ypt1 have been identified as important regulators of autophagy in mammalian and yeast cells, respectively (Huang et al. 2011; Lipatova et al. 2012; Lynch-Day et al. 2010; Mochizuki et al. 2013; Winslow et al. 2010; Zoppino et al. 2010). Interestingly, their functions are related to another membrane source for autophagosome biogenesis, that is, trans-Golgi/endosomal vesicles marked by the transmembrane protein Atg9. In yeast, the recruitment of Atg9 vesicles to the site of autophagosome formation depends on the activation of Ypt1 by TRAPPIII (Kakuta et al. 2012). 
In mammalian cells, the delivery of Atg9 from recycling endosomes to the IC/cis-Golgi was shown to depend on a molecular link between Rab11 and Rab1, which leads TRAPPIII-mediated activation of the latter (Lamb et al. 2015). Thus, a similar autophagy-related activation mechanism of Rab1/Ypt1, involving coupling between the IC and trans-Golgi/endosomal compartments, seems to operate in both yeast and mammals.

\section{Protein maturation}

By retrieving incompletely folded or assembled proteins in COPI-vesicles the IC/cis-Golgi system collaborates with the ER in a quality control process ensuring that only mature proteins reach the Golgi apparatus (Anelli and Sitia 2008; Barlowe and Helenius 2016, Hsu et al. 1991; Roth and Zuber 2017). Accordingly, the IC is the site of localization of glucosidase II and UDP-glucose: glycoprotein glucosyltransferase, key components of the quality control machinery (Lucocq et al. 1986; Zuber et al. 2001). In addition, the KDEL-containing molecular chaperones present in the IC-such as BiP, PDI and calreticulin (Breuza et al. 2004; Zuber et al. 2001)—could cycle bound to their unfolded client proteins, enabling post-ER quality control (Hammond and Helenius 1994). For example, ERp44 (a PDI family member) and $\mathrm{BiP}$ interact in the $\mathrm{IC} / c i s$-Golgi in a pHdependent manner with the KDEL-receptor, resulting in ER retrieval of their clients, unassembled IgM or T-cell antigen receptor subunits, respectively (Vavassori et al. 2013; Yamamoto et al. 2001). Moreover, a recent study demonstrated the COPI-dependent cycling of neurodegeneration-related mutant membrane proteins in the early secretory pathway (Sirkis et al. 2017). Additional evidence for the function of the IC/cis-Golgi as a post-ER quality control checkpoint is provided by the observed accumulation misfolded proteins in the IC elements (Hermosilla et al. 2004; Raposo et al. 1995; Zuber et al. 2004).

\section{Signaling}

A number of protein kinases have been implicated in the regulation of COPI-dependent retrograde trafficking at the IC/cis-Golgi level (Hamlin et al. 2014; Tisdale and Artalejo 2006). Notably, the KDEL-receptor-a seven-spanning transmembrane protein reminiscent of cell surface $G$ protein-coupled receptors-is a key component of a homeostatic control system that regulates antero- and retrograde trafficking at the ER-Golgi interface and across the Golgi stacks (Cancino et al. 2014). The receptor senses incoming transport fluxes due to binding of KDEL-proteins, leading to interaction with two different Golgi-associated heterotrimeric G-proteins. The latter activate Src-kinases, which regulate the transport machineries via phosphorylation
(Giannotta et al. 2012; Pulvirenti et al. 2008). Recently, the interaction of the KDEL-receptor with still another G-protein was shown to activate a conserved signaling path that involves Rab1 and controls the formation of cellular protrusions, such as neurites (Solis et al. 2017). This finding in relevant in terms of the previously demonstrated, Rab1mediated Golgi bypass route from the IC to the neurite-like extensions and growth cones of PC12 cells (Sannerud et al. 2006).

\section{Implications of the stable IC-endosome connection for Golgi biogenesis}

The separation and pericentrosomal expansion of the BRC and ERC in motile or dividing normal rat kidney (NRK) cells (Marie et al. 2009, 2012, Fig. 6) coincide with the fragmentation of the Golgi ribbon (Acharya et al. 1998; Bisel et al. 2008). Based on this observation we proposed that these compartments are derived from the tubulovesicular networks that connect the different Golgi stacks (Marie et al. 2012). This is in accordance with EM tomographic data on the organization of the Golgi ribbon in NRK cells, showing that these "non-compact regions" contain pleiomorphic structures resembling IC elements or endosomes (Ladinsky et al. 1999). In addition, the existence of a Golgi bypass pathway in neuronal dendrites (Bowen et al. 2017) revealed that the functional connection between the IC elements and recycling endosomes does not depend on their close association with the centrosome.

The BFA-resistance and mitotic preservation of the IC elements and recycling endosomes suggest that they play key roles in Golgi biogenesis. The schematic model in Fig. 7 proposes that these stable compartments, occupying the linker regions of the Golgi ribbon, generate cisternal organization at the two sides of the Golgi stacks in a process that depends on the BFA-sensitive COPI and clathrin coats. Regarding the trans-side, the model is based on the existence of a AP-1/clathrin-dependent transport route from recycling endosomes to the trans-Golgi/TGN (Hinners and Tooze 2003; Lu and Hong 2014; Mallard et al. 1998; Matsudaira et al. 2015). Regarding cis-Golgi events, the model takes into account the function of COPI-coated tubules in anterograde transport at the level of the Golgi stacks (Park et al. 2015). Notably, the integrity of the Golgi ribbon depends on the formation of these tubules (Yang et al. 2011). As indicated in Fig. 7, disassembly of these coats by BFA blocks the two pathways (red arrows), resulting in rapid breakdown of the Golgi stacks. By contrast, the BFA-resistant "linker compartments"—defined by Rab1 and Rab11—persist and pile up around the centrosome. The BFA-induced redistribution of cis- and medial-Golgi enzymes, such as mannosidase II, to the ER occurs via the pericentrosomal IC tubules (Marie 


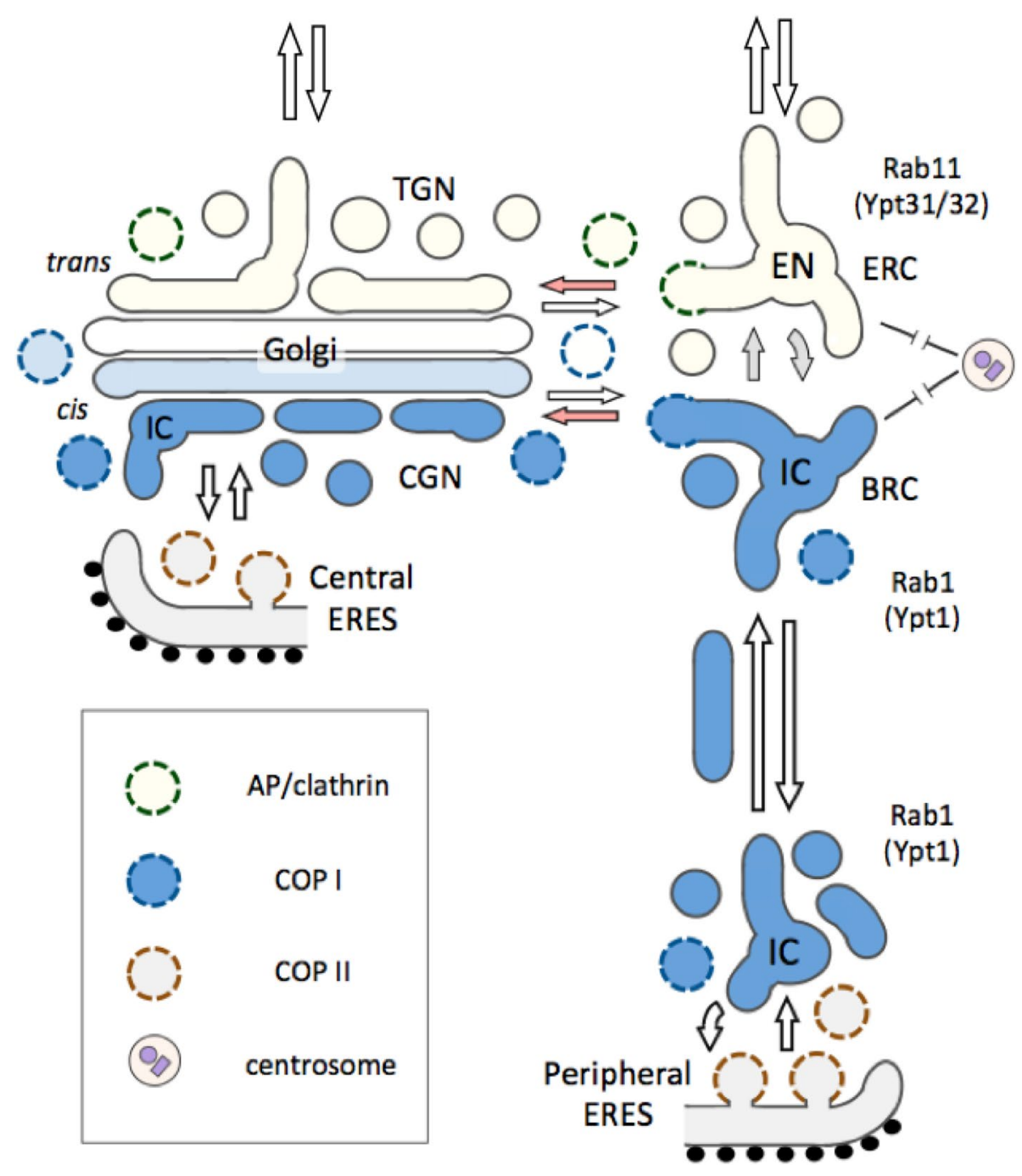

Fig. 7 Spatial and functional relationship of the biosynthetic (IC) and endosomal (EN) networks with the Golgi stacks. According to this model the "mirror compartments" BRC and ERC (Saraste and Goud 2007) normally exist within the Golgi ribbon at some distance from the centrosome. These tubular compartments develop from IC and endosomal structures that occupy the non-compact regions connecting the different Golgi stacks, but expand and accumulate around the centrosome, when the latter separates from the Golgi ribbon-for example, due to cell motility or division. In addition, the IC elements and recycling endosomes at the linker regions communicate bi-directionally with the Golgi stacks, perhaps preferentially with the tubular

et al. 2009), supporting this model. On the other hand, TGN markers-such as furin and TGN38 - that cycle between trans-Golgi/TGN and the endosomal system accumulate around the centrosome in BFA-treated cells, suggesting that their normal retrieval from recycling endosomes to the TGN is blocked (Molloy et al. 1994; Reaves and Banting 1992). Thus, coat-independent pathways remain operational in BFA-treated cells, resulting in the redistribution of Golgi components. The COPI-independent tubular pathway that is networks at the cis- and trans-sides of the organelle (CGN and TGN). The red arrows indicate Arf1-regulated, COPI- or clathrin-dependent transport steps, which are blocked by BFA. The same transport steps could be inhibited at the onset of mitosis due to phosphorylation of key regulatory components, leading to Golgi fragmentation. The Rab GTPases regulating transport at the level of the BRC and ERC (Rab1 and Rab11), and the early and late Golgi compartments of S. cerevisiae (Ypt1 and Ypt31/32) have been indicated, suggesting a close relationship of the tubular networks operating in the mammalian and yeast secretory pathways (Jackson 2009; Marie et al. 2008)

regulated by Rab6 may participate in these events (Heffernan and Simpson 2014; Sengupta et al. 2015).

The model in Fig. 7 is also supported by the data on the localization of the BFA-sensitive GEFs, GBF1 and BIG1/ BIG2, that activate Arf1 at the two sides of the Golgi ribbon, thereby regulating the recruitment of COPI and clathrin coats. Namely, GBF1 is predominantly localized to the IC/cis-Golgi, while BIG1/BIG2 are present in both recycling endosomes and trans-Golgi/TGN (Ishizaki et al. 2008; Shen et al. 2006; Togawa et al. 1999; Zhao et al. 2006). Indeed, 
previous studies demonstrated that the knock-down of GBF1 and BIGs results in disassembly of the Golgi stacks and the trans-Golgi/TGN, respectively (Manolea et al. 2008).

The present model could also apply to the events that take place at the onset of mitosis (Ayala and Colanzi 2017). The phosphorylation of key machinery proteins at the $\mathrm{G}_{2} / \mathrm{M}$ transition-such as GRASP55, GRASP65 and possibly also BARS—could affect the same step(s) as BFA (Fig. 7, red arrows), but in this case resulting initially in the fragmentation of the Golgi ribbon. Notably, mitotic progression could depend on proper detachment of the linker compartments from the Golgi ribbon and their accumulation around the centrosome (Fig. 6; Marie et al. 2012).

The relationships of the compartments at the cis- and trans-sides of the Golgi-the IC and cis-Golgi/CGN and recycling endosomes and the trans-Golgi/TGN, respectively-have been difficult to define, due to their spatial overlap and compositional and functional similarities. The biogenetic relationship between these compartments, proposed in Fig. 7, can explain why machinery proteins operating at the level of pre-Golgi IC or post-Golgi recycling endosomes are also invariably found at the cis- and transsides of the Golgi stacks. The placement of the IC and recycling endosomes as linker compartments in the Golgi ribbon could also clarify the spatial relationship between pathways that involve classical Golgi passage or bypass the cisternal stacks. In addition, the "Golgi bypass route" depicted in Fig. 7 could be utilized to generate the polarized distribution of Golgi components (Marie et al. 2008). It could also give rise to aberrant cell surface delivery of proteins under conditions when their normal routes are compromised. Furthermore, the model in Fig. 7 opens up the possibility that COPI vesicles at the non-compact regions (Ladinsky et al. 1999; Rabouille and Klumperman 2005; Yang et al. 2008) mediate the cycling of Golgi enzymes between the linker compartments and the Golgi stacks (Alvarez et al. 1999; Jarvela and Linstedt, 2011). Encountering the mildly acidic luminal milieu of the linker compartments (Palokangas et al. 1998; Yamashiro et al. 1984) could regulate the assembly of the glycosyltransferase complexes (Hassinen and Kellokumpu 2014).

Finally, the present model on the role of the interconnected biosynthetic (IC) and endocytic tubular networks in the biogenesis of the Golgi stacks can explain the relationship between the yeast and mammalian secretory systems. Accordingly, the yeast pathway consisting of tubular networks, some with combined secretory and endocytic activities (Day et al. 2018), is likely to represent a primordial endomembrane system that is employed by mammalian cells as the basis for the build-up of the Golgi ribbon (Fig. 7; Jackson 2009; Marie et al. 2008). An obvious difference is that the tubular networks in the mammalian cells have been linked to the radiating MT system that is anchored to the centrosome.

\section{Summary and perspectives}

Based on recent imaging studies, the main message of this review is that the IC-instead of corresponding to a collection of transient transport carriers operating between the ER and the Golgi stacks-represents a permanent membrane system that extends throughout the cytoplasm. The stable nature of the IC is supported by recent findings showing that this compartment has multiple functions that are not all necessarily related to ER-Golgi communication. Moreover, the behavior of the IC during mitosis shows its stability and autonomy from the ER and Golgi. Notably, however, the joint division of the BRC and ERC at the onset of mitosis (Fig. 6) demonstrates the close partnership of the biosynthetic (IC) and endocytic tubular networks, which also appear to communicate during interphase. Indeed, we can see the BRC-ERC link again at the cell center, when these compartments pile up around the centrosome during Golgi repositioning in motile cells (Marie et al. 2009; Dale et al. in preparation). Also, recent studies indicate that they join forces at more peripheral sites, possibly including the Golgi ribbon, as suggested in Fig. 7. An intimate spatial and functional connection between these networks could expain mutant cells, where both secretion and endocytosis are affected (Gao et al. 1994; Kao and Draper 1992), as well as the appearance of IC/cis-Golgi proteins in "wrong" places at the outskirts of the cell (Kaczmarek et al. 2017; Sannerud et al. 2006).

Morphological studies employing an ever-increasing repertoire of advanced light and electron microscopic techniques, including super-resolution microscopy, can be expected to also play a key role in future studies aimed at the elucidation of the functional organization of the IC and its relation with the Golgi stacks and the endosomal system. As demonstrated by recent studies on neurons (Bourke et al. 2018; Bowen et al. 2017; Hanus and Ehlers 2016; Mikhaylova et al. 2016), examination of specialized cell types, such as epithelial and muscle cells, can also help to reveal additional secrets of this fascinating membrane system.

Acknowledgements We are grateful to Dr. Kristian Prydz for helpful discussions, critical evaluation of the manuscript and numerous valuable suggestions. The work in the Saraste lab is supported by the University of Bergen and the Research Council of Norway (Småforsk) and the Nansen Foundation.

Open Access This article is distributed under the terms of the Creative Commons Attribution 4.0 International License (http://creativeco mmons.org/licenses/by/4.0/), which permits unrestricted use, distribution, and reproduction in any medium, provided you give appropriate 
credit to the original author(s) and the source, provide a link to the Creative Commons license, and indicate if changes were made.

\section{References}

Acharya U, Mallabiabarrena A, Acharya JK, Malhotra V (1998) Signaling via mitogen-activated protein kinase kinase (MEK1) is required for Golgi fragmentation during mitosis. Cell 92:183-192

Aizawa M, Fukuda M (2015) Small GTPase Rab2B and its specific binding protein Golgi- associated Rab2B interactorlike 4 (GARI-L4) regulate Golgi morphology. J Biol Chem 290:22250-22261

Alberts B, Johnson A, Lewis J, Raff M, Roberts K, Walter P (2002) Molecular biology of the cell, 4 edn. Garland Science, New York

Allan BB, Moyer BD, Balch WE (2000) Rab1 recruitment of p115 into a cis-SNARE complex: programming budding COPII vesicles for fusion. Science 289:444-448

Alvarez C, Fujita H, Hubbard A, Sztul E (1999) ER to Golgi transport: requirement for p115 at a pre-Golgi VTC stage. J Cell Biol 147:1205-1222

Alvarez C, Garcia-Mata R, Brandon E, Sztul E (2003) COPI recruitment is modulated by a Rab1b-dependent mechanism. Mol Biol Cell 14:2116-2127

Anelli T, Sitia R (2008) Protein quality control in the early secretory pathway. EMBO J 27:315-327

Aniento F, Gu F, Parton RG, Gruenberg J (1996) An endosomal beta $\mathrm{COP}$ is involved in the $\mathrm{pH}$-dependent formation of transport vesicles destined for late endosomes. J Cell Biol 133:29-41

Appenzeller C, Andersson H, Kappeler F, Hauri HP (1999) The lectin ERGIC-53 is a cargo transport receptor for glycoproteins. Nat Cell Biol 1:330-334

Appenzeller-Herzog C, Hauri HP (2006) The ER-Golgi intermediate compartment (ERGIC): in search of its identity and function. $\mathrm{J}$ Cell Sci 119:2173-2183

Appenzeller-Herzog C, Roche AC, Nufer O, Hauri HP (2004) pHinduced conversion of the transport lectin ERGIC-53 triggers glycoprotein release. J Biol Chem 279:12943-12950

Arar C, Carpentier V, Le Caer JP et al (1995) ERGIC-53, a membrane protein of the endoplasmic reticulum-Golgi intermediate compartment, is identical to MR60, an intracellular mannose-specific lectin of myelomonocytic cells. J Biol Chem 270:3551-3553

Ayala J (1994) Transport and internal organization of membranes: vesicles, membrane networks and GTP-binding proteins. J Cell Sci 107:753-763

Ayala I, Colanzi A (2017) Mitotic inheritance of the Golgi complex and its role in cell division. Biol Cell 109:364-374

Balch WE (1990) Molecular dissection of early stages of the eukaryotic secretory pathway. Curr Opin Cell Biol 2:634-641

Balch WE, Elliott MM, Keller DD (1986) ATP-coupled transport of vesicular stomatitis virus $\mathrm{G}$ protein between the endoplasmic reticulum and Golgi. J Biol Chem 261:14681-14689

Balch WE, McCaffery JM, Plutner H, Farquhar MG (1994) Vesicular stomatitis virus glycoprotein is sorted and concentrated during export from the endoplasmic reticulum. Cell 76:841-852

Baldwin TA, Ostergaard HL (2002) The protein-tyrosine phosphatase CD45 reaches the cell surface via Golgi-dependent and -independent pathways. J Biol Chem 277:50333-50340

Bannykh SI, Balch WE (1997) Membrane dynamics at the endoplasmic reticulum-Golgi interface. J Cell Biol 138:1-4

Bannykh SI, Rowe T, Balch WE (1996) The organization of endoplasmic reticulum export complexes. J Cell Biol 135:19-35

Barlowe C, Helenius A (2016) Cargo capture and bulk flow in the early secretory pathway. Annu Rev Cell Dev Biol 32:197-222
Barlowe CK, Miller EA (2013) Secretory protein biogenesis and traffic in the early secretory pathway. Genetics 193:383-410

Bechler ME, de Figueiredo P, Brown WJ (2012) A PLA1-2 punch regulates the Golgi complex. Trends Cell Biol 22:116-124

Behnia R, Munro S (2005) Organelle identity and the signposts for membrane traffic. Nature 438:597-604

Ben-Tekaya H, Miura K, Pepperkok R, Hauri HP (2005) Live imaging of bidirectional traffic from the ERGIC. J Cell Sci 118:357-367

Ben-Tekaya H, Kahn RA, Hauri HP (2010) ADP ribosylation factors 1 and 4 and group VIA phospholipase A2 regulate morphology and intraorganellar traffic in the endoplasmic reticulum-Golgi intermediate compartment. Mol Biol Cell 21:4130-4140

Bergmann JE, Tokuyasu KT, Singer SJ (1981) Passage of an integral membrane protein, the vesicular stomatitis virus glycoprotein, through the Golgi apparatus en route to the plasma membrane. Proc Natl Acad Sci USA 78:1746-1750

Bisel B, Wang Y, Wei JH et al (2008) ERK regulates Golgi and centrosome orientation towards the leading edge through GRASP65. J Cell Biol 182:837-843

Blum R, Pfeiffer F, Feick P et al (1999) Intracellular localization and in vivo trafficking of p24A and p23. J Cell Sci 112:537-548

Blum R, Stephens DJ, Schulz I (2000) Lumenal targeted GFP, used as a marker of soluble cargo, visualises rapid ERGIC to Golgi traffic by a tubulo-vesicular network. J Cell Sci 113:3151-3159

Bonatti S, Torrisi MR (1993) The intermediate compartment between endoplasmic reticulum and Golgi complex in mammalian cells. Subcell Biochem 21:121-142

Bonatti S, Migliaccio G, Simons K (1989) Palmitylation of viral membrane glycoproteins takes place after exit from the endoplasmic reticulum. J Biol Chem 264:12590-12595

Bonifacino JS, Glick BS (2004) The mechanisms of vesicle budding and fusion. Cell 116:153-166

Bonifacino JS, Lippincott-Schwartz J (2003) Coat proteins: shaping membrane transport. Nat Rev Mol Cell Biol 4:409-414

Bottanelli F, Kilian N, Ernst AM et al (2017) A novel physiological role for Arf1 in the formation of bidirectional tubules from the Golgi. Mol Biol Cell 28:1676-1687

Bourke AM, Bowen AB, Kennedy MJ (2018) New approaches for solving old problems in neuronal protein trafficking. Mol Cell Neurosci. https://doi.org/10.1016/j.mcn.2018.04.004

Bowen AB, Bourke AM, Hiester BG, Hanus C, Kennedy MJ (2017) Golgi-independent secretory trafficking through recycling endosomes in neuronal dendrites and spines. Elife 6:89. https:// doi.org/10.7554/eLife.27362

Brandizzi F, Barlowe C (2013) Organization of the ER-Golgi interface for membrane traffic control. Nat Rev Mol Cell Biol 14:382-392

Breuza L, Halbeisen R, Jenö P et al (2004) Proteomics of endoplasmic reticulum-Golgi intermediate compartment (ERGIC) membranes from brefeldin A-treated HepG2 cells identifies ERGIC-32, a new cycling protein that interacts with human Erv46. J Biol Chem 279:47242-47253

Brown AK, Hunt SD, Stephens DJ (2014) Opposing microtubule motors control motility, morphology and cargo segregation during ER-to-Golgi transport. Biol Open 3:307-313. https://doi. org/10.1242/bio.20147633

Bu G, Geuze HJ, Strous GJ, Schwartz AL (1995) Binding and endocytosis of $39 \mathrm{kDa}$ protein by MDBK cells. EMBO J 14:2269-2280

Burgess TL, Kelly RB (1987) Constitutive and regulated secretion of proteins. Annu Rev Cell Biol 3:243-293

Burkhardt JK, Echeverri CJ, Nilsson T, Vallee RB (1997) Overexpression of the dynamitin (p50) subunit of the dynactin complex disrupts dynein-dependent maintenance of membrane organelle distribution. J Cell Biol 139:469-484

Campellone KG, Webb NJ, Znameroski EA, Welch MD (2008) WHAMM is an Arp $2 / 3$ complex activator that binds microtubules and functions in ER to Golgi transport. Cell 134:148-161 
Cancino J, Capalbo A, Di Campli A (2014) Control systems of membrane transport at the interface between the endoplasmic reticulum and the Golgi. Dev Cell 30:280-294. https://doi. org/10.1016/j.devcel.2014.06.018

Chao DS, Hay JC, Winnick S et al (1999) SNARE membrane trafficking dynamics in vivo. J Cell Biol 144:869-881

Chun J, Shapovalova Z, Dejgaard SY, Presley JF, Melançon P (2008) Characterization of class I and class II ADP-ribosylation factors in live cells: GDP-bound class II Arfs associate with the ERGolgi intermediate compartment independently of GBF1. Mol Biol Cell 19:3488-3500

Cortini M, Sitia R (2010) ERp44 and ERGIC-53 synergize in coupling efficiency and fidelity of IgM polymerization and secretion. Traffic 11:651-659. https://doi.org/10.1111/j.1600-0854.2010.01043 .X

Cosson P, Letourneur F (1997) Coatomer (COPI)-coated vesicles: role in intracellular transport and protein sorting. Curr Opin Cell Biol 9:484-487

Dahm T, White J, Grill S, Füllekrug J, Stelzer EH (2001) Quantitative ER $<->$ Golgi transport kinetics and protein separation upon Golgi exit revealed by vesicular integral membrane protein 36 dynamics in live cells. Mol Biol Cell 12: 1481-1498.

Day KJ, Staehelin LA, Glick BS (2013) A three-stage model of Golgi structure and function. Histochem Cell Biol 140:239-249

Day KJ, Casler JC, Glick BS (2018) Budding yeast has a minimal endomembrane system. Dev Cell 44:56-72. https://doi.org/10.1016/j. devcel.2017.12.014

Donohoe BS, Kang BH, Gerl MJ et al (2013) cis-Golgi cisternal assembly and biosynthetic activation occur sequentially in plants and algae. Traffic 14:551-567

Duden R, Griffiths G, Frank R, Argos P, Kreis TE (1991) Beta-COP, a $110 \mathrm{kd}$ protein associated with non-clathrin-coated vesicles and the Golgi complex, shows homology to beta-adaptin. Cell 64:649-565

Fan JY, Roth J, Zuber C (2003) Ultrastructural analysis of transitional endoplasmic reticulum and pre-Golgi intermediates: a highway for cars and trucks. Histochem Cell Biol 120:455-463

Farhan H, Reiterer V, Kriz A et al (2008) Signal-dependent export of GABA transporter 1 from the ER-Golgi intermediate compartment is specified by a C-terminal motif. J Cell Sci 121:753-761

Füllekrug J, Sönnichsen B, Schäfer U et al (1997) Characterization of brefeldin A-induced vesicular structures containing cycling proteins of the intermediate compartment/cis-Golgi network. FEBS Lett 404:75-81

Galea G, Bexiga MG, Panarella A, O’Neill ED, Simpson JC (2015) A high-content screening microscopy approach to dissect the role of Rab proteins in Golgi-to-ER retrograde trafficking. J Cell Sci 128:2339-2349

Ge L, Melville D, Zhang M, Schekman R (2013) The ER-Golgi intermediate compartment is a key membrane source for the LC3 lipidation step of autophagosome biogenesis. Elife 2:e00947. https://doi.org/10.7554/eLife.00947

Ge L, Zhang M, Kenny SJ et al (2017) Remodeling of ER-exit sites initiates a membrane supply pathway for autophagosome biogenesis. EMBO Rep 18:1586-1603. https://doi.org/10.15252/ embr.201744559

Gee HY, Noh SH, Tang BL, Kim KH, Lee MG (2011) Rescue of $\triangle$ F508-CFTR trafficking via a GRASP- dependent unconventional secretion pathway. Cell 146:746-760

Giannotta M, Ruggiero C, Grossi M et al (2012) The KDEL receptor couples to $\mathrm{G} \alpha \mathrm{q} / 11$ to activate Src kinases and regulate transport through the Golgi. EMBO J 31:2869-2881. https://doi. org/10.1038/emboj.2012.134

Gilbert CE, Sztul E, Machamer C (2018) Commonly used trafficking blocks disrupt Arf1 activation and the localization and function of specific Golgi proteins. Mol Biol Cell 29:937-947. https://doi. org/10.1091/mbc.E17-11-0622

Gilchrist A, Au CE, Hiding J et al (2006) Quantitative proteomics analysis of the secretory pathway. Cell 127:1265-1281

Gill DJ, Chia J, Senewiratne J, Bard F (2010) Regulation of O-glycosylation through Golgi-to-ER relocation of initiation enzymes. J Cell Biol 189:843-858

Gillingham AK, Munro S (2016) Finding the Golgi: golgin coiled-coil proteins show the way. Trends Cell Biol 26:399-408

Gomez-Navarro N, Miller E (2016) Protein sorting at the ER-Golgi interface. J Cell Biol 215:769-778

Gosavi P, Gleeson PA (2017) The function of the Golgi ribbon structure-an enduring mystery unfolds! Bioessays 39. https://doi. org/10.1002/bies.201700063

Goud B, Liu S, Storrie B (2018) Rab proteins as major determinants of the Golgi complex structure. Small GTPases 9:66-75. https:// doi.org/10.1080/21541248.2017.1384087

Griffiths G, Ericsson M, Krijnse-Locker J et al (1994) Localization of the Lys, Asp, Glu, Leu tetrapeptide receptor to the Golgi complex and the intermediate compartment in mammalian cells. J Cell Biol 127:1557-1574

Griffiths G, Pepperkok R, Locker JK, Kreis TE (1995) Immunocytochemical localization of beta-COP to the ER-Golgi boundary and the TGN. J Cell Sci 108:2839-2856

Guo Q, Vasile E, Krieger M (1994) Disruptions in Golgi structure and membrane traffic in a conditional lethal mammalian cell mutant are corrected by epsilon-COP. J Cell Biol 125:1213-1224

Gurel PS, Hatch AL, Higgs HN (2014) Connecting the cytoskeleton to the endoplasmic reticulum and Golgi. Curr Biol 24:R660-R672. https://doi.org/10.1016/j.cub.2014.05.033

Haas AK, Yoshimura S, Stephens DJ, Preisinger C, Fuchs E, Barr FA (2007) Analysis of GTPase-activating proteins: Rab1 and Rab43 are key Rabs required to maintain a functional Golgi complex in human cells. J Cell Sci 120:2997-3010

Hamlin JN, Schroeder LK, Fotouhi M et al (2014) Scyl1 scaffolds class II Arfs to specific sub- complexes of coatomer through the $\gamma$-COP appendage domain. J Cell Sci 127:1454-1463

Hammond AT, Glick BS (2000) Dynamics of transitional endoplasmic reticulum sites in vertebrate cells. Mol Biol Cell 11:3013-3030

Hammond C, Helenius A (1994) Quality control in the secretory pathway: retention of a misfolded viral membrane glycoprotein involves cycling between the ER, intermediate compartment, and Golgi apparatus. J Cell Biol 126:41-52

Hanna MG, Peotter JL, Frankel EB, Audhya A (2018) Membrane transport at an organelle interface in the early secretory pathway: take your coat off and stay a while: evolution of the metazoan early secretory pathway. Bioessays. https://doi.org/10.1002/bies.20180 0004

Hanus C, Ehlers MD (2016) Specialization of biosynthetic membrane trafficking for neuronal form and function. Curr Opin Neurobiol 39:8-16. https://doi.org/10.1016/j.conb.2016.03.004

Hanus C, Kochen L, Tom Dieck S et al (2014) Synaptic control of secretory trafficking in dendrites. Cell Rep 7:1771-1778. https ://doi.org/10.1016/j.celrep.2014.05.028

Hanus C, Geptin H, Tushev G et al (2016) Unconventional secretory processing diversifies neuronal ion channel properties. Elife 5. https://doi.org/10.7554/eLife.20609

Hassinen A, Kellokumpu S (2014) Organizational interplay of Golgi $\mathrm{N}$-glycosyltransferases involves organelle microenvironmentdependent transitions between enzyme homo- and heteromers. J Biol Chem 289:26937-226948. https://doi.org/10.1074/jbc. M114.595058

Haubruck H, Prange R, Vorgias C, Gallwitz D (1989) The ras-related mouse ypt 1 protein can functionally replace the YPT1 gene product in yeast. EMBO J 8:1427-1432 
Hauri HP, Schweizer A (1992) The endoplasmic reticulum-Golgi intermediate compartment. Curr Opin Cell Biol 4:600-608

Heffernan LF, Simpson JC (2014) The trials and tubule-ations of Rab6 involvement in Golgi-to-ER retrograde transport. Biochem Soc Trans 42:1453-1459. https://doi.org/10.1042/BST20140178

Hermosilla R, Oueslati M, Donalies U et al (2004) Disease-causing $\mathrm{V}(2)$ vasopressin receptors are retained in different compartments of the early secretory pathway. Traffic 5:993-1005

Hinners I, Tooze SA (2003) Changing directions: clathrin-mediated transport between the Golgi and endosomes. J Cell Sci 116:763-771

Hopkins CR, Gibson A, Shipman M, Miller K (1990) Movement of internalized ligand-receptor complexes along a continuous endosomal reticulum. Nature 346:335-339

Horstman H, Ng CP, Tang BL, Hong W (2002) Ultrastructural characterization of endoplasmic reticulum-Golgi transport containers (EGTC). J Cell Sci 115:4263-4273

Hosobuchi M, Kreis T, Schekman R (1992) SEC21 is a gene required for ER to Golgi protein transport that encodes a subunit of a yeast coatomer. Nature 360:603-605

Hsu VW, Yuan LC, Nuchtern JG et al (1991) A recycling pathway between the endoplasmic reticulum and the Golgi apparatus for retention of unassembled MHC class I molecules. Nature 352:441-444

Hsu NY, Ilnytska O, Belov G et al (2010) Viral reorganization of the secretory pathway generates distinct organelles for RNA replication. Cell 141:799-811

Huang J, Birmingham CL, Shahnazari S et al (2011) Antibacterial autophagy occurs at PI(3)P- enriched domains of the endoplasmic reticulum and requires Rab1 GTPase. Autophagy 7:17-26

Hutagalung AH, Novick PJ (2011) Role of Rab GTPases in membrane traffic and cell physiology. Physiol Rev 91:119-149. https://doi. org/10.1152/physrev.00059.2009

Huttner WB, Tooze SA (1989) Biosynthetic protein transport in the secretory pathway. Curr Opin Cell Biol 1:648-654

Ishizaki R, Shin HW, Mitsuhashi H, Nakayama K (2008) Redundant roles of BIG2 and BIG1, guanine-nucleotide exchange factors for ADP-ribosylation factors in membrane traffic between the transGolgi network and endosomes. Mol Biol Cell 19:2650-2660. https://doi.org/10.1091/mbc.E07-10-1067

Itin C, Roche AC, Monsigny M, Hauri HP (1996) ERGIC-53 is a functional mannose-selective and calcium-dependent human homologue of leguminous lectins. Mol Biol Cell 7:483-493

Ito Y, Uemura T, Nakano A (2018) The Golgi entry core compartment functions as a COPII- independent scaffold for ER-to-Golgi transport in plant cells. J Cell Sci 131. https://doi.org/10.1242/ jcs. 203893

Jackson CL (2009) Mechanisms of transport through the Golgi complex. J Cell Sci 122:443-452. https://doi.org/10.1242/jcs.032581

Jackson MR, Nilsson T, Peterson PA (1990) Identification of a consensus motif for retention of transmembrane proteins in the endoplasmic reticulum. EMBO J 9:3153-3162

Jäntti J, Hildén P, Rönkä H et al (1997) Immunocytochemical analysis of Uukuniemi virus budding compartments: role of the intermediate compartment and the Golgi stack in virus maturation. $\mathrm{J}$ Virol 71:1162-1172

Jarvela T, Linstedt AD (2012) Irradiation-induced protein inactivation reveals Golgi enzyme cycling to cell periphery. J Cell Sci 125:973-980

Jönsson M, Eklund E, Fransson LA, Oldberg A (2003) Initiation of the decorin glycosaminoglycan chain in the endoplasmic reticulumGolgi intermediate compartment. J Biol Chem 278:21415-21420

Kaczmarek B, Verbavatz JM, Jackson CL (2017) GBF1 and Arf1 function in vesicular trafficking, lipid homoeostasis and organelle dynamics. Biol Cell 109:391-399. https://doi.org/10.1111/ boc. 201700042
Kakuta S, Yamamoto H, Negishi L, Kondo-Kakuta C, Hayashi N, Ohsumi Y (2012) Atg9 vesicles recruit vesicle-tethering proteins Trs85 and Ypt1 to the autophagosome formation site. J Biol Chem 287:44261-44429. https://doi.org/10.1074/jbc. M112.411454

Kamena F, Diefenbacher M, Kilchert C, Schwarz H, Spang A (2008) Ypt1p is essential for retrograde Golgi-ER transport and for Golgi maintenance in S. cerevisiae. J Cell Sci 121:1293-1302

Kao CY, Draper RK (1992) Retention of secretory proteins in an intermediate compartment and disappearance of the Golgi complex in an END4 mutant of chinese hamster ovary cells. J Cell Biol 117:701-715

Kappeler F, Klopfenstein DR, Foguet M, Paccaud JP, Hauri HP (1997) The recycling of ERGIC-53 in the early secretory pathway. ERGIC-53 carries a cytosolic endoplasmic reticulum-exit determinant interacting with COPII. J Biol Chem 272:31801-31808

Karanasios E, Walker SA, Okkenhaug H et al (2016) Autophagy initiation by ULK complex assembly on ER tubulovesicular regions marked by ATG9 vesicles. Nat Commun 1:12420. https://doi. org/10.1038/ncomms 12420

Kelly RB (1990) Microtubules, membrane traffic, and cell organization. Cell 61:5-7

Klumperman J, Locker JK, Meijer A et al (1994) Coronavirus M proteins accumulate in the Golgi complex beyond the site of virion budding. J Virol 68:6523-6534

Klumperman J, Schweizer A, Clausen H et al (1998) The recycling pathway of protein ERGIC-53 and dynamics of the ER-Golgi intermediate compartment. J Cell Sci 111:3411-3425

Klute MJ, Melançon P, Dacks JB (2011) Evolution and diversity of the Golgi. Cold Spring Harb Perspect Biol 3:a007849. https://doi. org/10.1101/cshperspect.a007849

Kondylis V, Rabouille C (2009) The Golgi apparatus: lessons from Drosophila. FEBS Lett 583:3827-3838. https://doi.org/10.1016/j. febslet.2009.09.048

Krijnse-Locker J, Ericsson M, Rottier PJ, Griffiths G (1994) Characterization of the budding compartment of mouse hepatitis virus: evidence that transport from the RER to the Golgi complex requires only one vesicular transport step. J Cell Biol 124:55-70

Krijnse-Locker J, Parton RG, Fuller SD, Griffiths G, Dotti CG (1995) The organization of the endoplasmic reticulum and the intermediate compartment in cultured rat hippocampal neurons. Mol Biol Cell 6:1315-1332

Kuismanen E, Saraste J (1989) Low temperature-induced transport blocks as tools to manipulate membrane traffic. Meth Cell Biol $32: 257-274$

Kurokawa K, Okamoto M, Nakano A (2014) Contact of cis-Golgi with ER exit sites executes cargo capture and delivery from the ER. Nat Commun 5:3653-3659

Ladinsky MS, Mastronarde DN, McIntosh JR, Howell KE, Staehelin LA (1999) Golgi structure in three dimensions: functional insights from the normal rat kidney cell. J Cell Biol 144:1135-1149

Lahtinen U, Dahllöf B, Saraste J (1992) Characterization of a 58 $\mathrm{kDa}$ cis-Golgi protein in pancreatic exocrine cells. J Cell Sci 103:321-333

Lahtinen U, Hellman U, Wernstedt C, Saraste J, Pettersson RF (1996) Molecular cloning and expression of a $58-\mathrm{kDa}$ cis-Golgi and intermediate compartment protein. J Biol Chem 271:4031-4037

Lamb CA, Nühlen S, Judith D et al (2015) TBC1D14 regulates autophagy via the TRAPP complex and ATG9 traffic. EMBO J 35:281-301. https://doi.org/10.15252/embj.201592695

Lavieu G, Zheng H, Rothman JE (2013) Stapled Golgi cisternae remain in place as cargo passes through the stack. Elife 2:e0558. https ://doi.org/10.7554/eLife.00558

Lavieu G, Dunlop MH, Lerich A, Zheng H, Bottanelli F, Rothman JE (2014) The Golgi ribbon structure facilitates anterograde 
transport of large cargoes. Mol Biol Cell 25:3028-3036. https:// doi.org/10.1091/mbc.E14-04-0931

Lazzarino DA, Gabel CA (1988) Biosynthesis of the mannose-6-phosphate recognition marker in transport-impaired mouse lymphoma cells. Demonstration of a two-step phosphorylation. J Biol Chem 263:10118-10126

Lee MC, Miller EA, Goldberg J, Orci L, Schekman R (2004) Bi-directional protein transport between the ER and Golgi. Annu Rev Cell Dev Biol 20:87-123

Lewis MJ, Pelham HR (1990) A human homologue of the yeast HDEL receptor. Nature 348:162-163

Lipatova Z, Belogortseva N, Zhang XQ et al (2012) Regulation of selective autophagy onset by a Ypt/Rab GTPase module. Proc Natl Acad Sci USA 109:6981-6986

Lipatova Z, Hain AU, Nazarko VY, Segev N (2015) Ypt/Rab GTPases: principles learned from yeast. Crit Rev Biochem Mol Biol 50:203-211

Lippincott-Schwartz J (1993) Membrane cycling between the ER and Golgi apparatus and its role in biosynthetic transport. Subcell Biochem 21:95-119

Lippincott-Schwartz J, Donaldson JG, Schweizer A et al (1990) Microtubule-dependent retrograde transport of proteins into the ER in the presence of brefeldin A suggests an ER recycling pathway. Cell 60:821-836

Lippincott-Schwartz J, Cole NB, Marotta A, Conrad PA, Bloom GS (1995) Kinesin is the motor for microtubule-mediated Golgi-toER membrane traffic. J Cell Biol 128:293-306

Lippincott-Schwartz J, Cole N, Presley J (1998) Unravelling Golgi membrane traffic with green fluorescent protein chimeras. Trends Cell Biol 8:16-20

Lorente-Rodríguez A, Barlowe C (2011) Entry and exit mechanisms at the cis-face of the Golgi complex. Cold Spring Harb Perspect Biol. https://doi.org/10.1101/cshperspect.a005207

Lotti LV, Torrisi MR, Pascale MC, Bonatti S (1992) Immunocytochemical analysis of the transfer of vesicular stomatitis virus $G$ glycoprotein from the intermediate compartment to the Golgi complex. J Cell Biol 118:43-50

Lowe M, Kreis TE (1998) Regulation of membrane traffic in animal cells by COPI. Biochim Biophys Acta 1404:53-66

Lu L, Hong W (2014) From endosomes to the trans-Golgi network. Semin Cell Dev Biol 31:30-39. https://doi.org/10.1016/j.semcd b.2014.04.024

Lucocq JM, Brada D, Roth J (1986) Immunolocalization of the oligosaccharide trimming enzyme glucosidase II. J Cell Biol 102:2137-2146

Lynch-Day MA, Bhandari D, Menon S et al (2010) Trs85 directs a Ypt1 GEF, TRAPPIII, to the phagophore to promote autophagy. Proc Natl Acad Sci USA 107:7811-7816

Machamer CE, Mentone SA, Rose JK, Farquhar MG (1990) The E1 glycoprotein of an avian coronavirus is targeted to the $c i s$-Golgi complex. Proc Natl Acad Sci USA 87:6944-6948

Majoul I, Straub M, Hell SW, Duden R, Söling HD (2001) KDELcargo regulates interactions between proteins involved in COPI vesicle traffic: measurements in living cells using FRET. Dev Cell 1:139-153

Mallard F, Antony C, Tenza D, Salamero J, Goud B, Johannes L (1998) Direct pathway from early/recycling endosomes to the Golgi apparatus revealed through the study of Shiga toxin B-fragment transport. J Cell Biol 143:973-990

Malsam J, Söllner TH (2011) Organization of SNAREs within the Golgi stack. Cold Spring Harb Perspect Biol 3:a005249. https:// doi.org/10.1101/cshperspect.a005249

Malsam J, Satoh A, Pelletier L, Warren G (2005) Golgin tethers define subpopulations of COPI vesicles. Science 307:1095-1098

Manolea F, Claude A, Chun J, Rosas J, Melancon P (2008) Distinct functions for Arf nucleotide exchange factors at the Golgi complex: GBF1 and BIGs are required for assembly and maintenance of the Golgi stack and TGN, respectively. Mol Biol Cell 19:523-535

Mansour SJ, Skaug J, Zhao XH, Giordano J, Scherer SW, Melançon P (1999) p200 ARF-GEP1: a Golgi-localized guanine nucleotide exchange protein whose Sec7 domain is targeted by the drug brefeldin A. Proc Natl Acad Sci USA 96:7968-7973

Marie M, Sannerud R, Dale HA, Saraste J (2008) Take the 'A' train: On fast tracks to the cell surface. Cell Mol Life Sci 65:2859-2874

Marie M, Dale HA, Sannerud R, Saraste J (2009) The function of the intermediate compartment in pre-Golgi trafficking involves its stable connection with the centrosome. Mol Biol Cell 20:4458-4470

Marie M, Dale HA, Kouprina N, Saraste J (2012) Division of the intermediate compartment at the onset of mitosis provides a mechanism for Golgi inheritance. J Cell Sci 125:5403-5416

Marra P, Salvatore L, Mironov A, Di Campli A, Di Tullio G, Trucco A, Beznoussenko G, Mironov A, De Matteis MA, Glick B (2007) The Biogenesis of the Golgi Ribbon: The Roles of Membrane Input from the ER and of GM130. Mol Biol Cell 18(5):1595-1608

Marsh M, Helenius A (1980) Adsorptive endocytosis of Semliki Forest virus. J Mol Biol 142:439-454

Martin PE, Blundell G, Ahmad S, Errington RJ, Evans WH (2001) Multiple pathways in the trafficking and assembly of connexin 26,32 and 43 into gap junction intercellular communication channels. J Cell Sci 114:3845-3855

Martínez-Alonso E, Egea G, Ballesta J, Martínez-Menárguez JA (2005) Structure and dynamics of the Golgi complex at $15{ }^{\circ} \mathrm{C}$ : Low temperature induces the formation of Golgi-derived tubules. Traffic 6:32-44

Martínez-Menárguez JA, Geuze HJ, Slot JW, Klumperman J (1999) Vesicular tubular clusters between the ER and Golgi mediate concentration of soluble secretory proteins by exclusion from COPI-coated vesicles. Cell 98:81-90

Matlin KS, Simons K (1983) Reduced temperature prevents transfer of a membrane glycoprotein to the cell surface but does not prevent terminal glycosylation. Cell 34:233-243

Matsudaira T, Niki T, Taguchi T, Arai H (2015) Transport of the cholera toxin B-subunit from recycling endosomes to the Golgi requires clathrin and AP-1. J Cell Sci 128:3131-3142. https:// doi.org/10.1242/jcs. 172171

Mellman I (2006) Endosomes come of age. In: Dikic I (ed) Endosomes. Landes Bioscience and Springer Science, New York, pp 1-13

Mellman I, Simons K (1992) The Golgi complex: in vitro veritas? Cell 68:829-840

Mikhaylova M, Bera S, Kobler O, Frischknecht R, Kreutz MR (2016) A dendritic Golgi satellite between ERGIC and retromer. Cell Rep 14:189-199. https://doi.org/10.1016/j.celrep.2015.12.024

Miller S, Krijnse-Locker J (2008) Modification of intracellular membrane structures for virus replication. Nat Rev Microbiol 6:363-374

Mironov AA, Mironov AA Jr, Beznoussenko GV et al (2003) ERto-Golgi carriers arise through direct en bloc protrusion and multistage maturation of specialized ER exit domains. Dev Cell 5:583-594

Mizuno-Yamasaki E, Rivera-Molina F, Novick P (2012) GTPase networks in membrane traffic. Annu Rev Biochem 81:637-659

Mochizuki Y, Ohashi R, Kawamura T et al (2013) Phosphatidylinositol 3-phosphatase myotubularin-related protein 6 (MTMR6) is regulated by small GTPase Rab1B in the early secretory and autophagic pathways. J Biol Chem 288:1009-1021

Molloy SS, Thomas L, VanSlyke JK, Stenberg PE, Thomas G (1994) Intracellular trafficking and activation of the furin proprotein convertase: localization to the TGN and recycling from the cell surface. EMBO J 13:18-33 
Monetta P, Slavin I, Romero N, Alvarez C (2007) Rab1B interacts with GBF1 and modulates both ARF1 dynamics and COPI association. Mol Biol Cell 18:2400-2410

Munro S, Pelham HR (1987) A C-terminal signal prevents secretion of luminal ER proteins. Cell 48:899-907

Nakano A, Luini A (2010) Passage through the Golgi. Curr Opin Cell Biol 22:471-478. https://doi.org/10.1016/j.ceb.2010.05.003

Nichols WC, Seligsohn U, Zivelin A et al (1998) Mutations in the ER-Golgi intermediate compartment protein ERGIC-53 cause combined deficiency of coagulation factors V and VIII. Cell 93:61-70

Nilsson T, Jackson M, Peterson PA (1989) Short cytoplasmic sequences serve as retention signals for transmembrane proteins in the endoplasmic reticulum. Cell 58:707-718

Oprins A, Duden R, Kreis TE, Geuze HJ, Slot JW (1993) Beta-COP localizes mainly to the cis-Golgi side in exocrine pancreas. J Cell Biol 121:49-59

Oprins A, Rabouille C, Posthuma G et al (2001) The ER-to-Golgi interface is the major concentration site of secretory proteins in the exocrine pancreatic cell. Traffic 2:831-838

Orci L, Stamnes M, Ravazzola M et al (1997) Bidirectional transport by distinct populations of COPI-coated vesicles. Cell 90:335-349

Palade GE (1975) Intracellular aspects of the process of protein secretion. Science 189:347-358

Palokangas H, Ying M, Väänänen K, Saraste J (1998) Retrograde transport from the pre-Golgi intermediate compartment and the Golgi complex is affected by the vacuolar $\mathrm{H}^{+}$-ATPase inhibitor bafilomycin A1. Mol Biol Cell 9:3561-3578

Papanikou E, Day KJ, Austin J, Glick BS (2015) COPI selectively drives maturation of the early Golgi. Elife 4. pii: e13232. https ://doi.org/10.7554/eLife.13232

Park SY, Yang JS, Schmider AB, Soberman RJ, Hsu VW (2015) Coordinated regulation of bidirectional COPI transport at the Golgi by CDC42. Nature 521:529-532

Pelham HR (1988) Evidence that luminal ER proteins are sorted from secreted proteins in a post- ER compartment. EMBO J 7:913-918

Pelham HR (1989) Control of protein exit from the endoplasmic reticulum. Annu Rev Cell Biol 5:1-23

Pepperkok R, Scheel J, Horstmann H et al (1993) $\beta$-COP is essential for biosynthetic membrane transport from the endoplasmic reticulum to the Golgi complex in vivo. Cell 74:71-82

Peter F, Plutner H, Zhu H, Kreis TE, Balch WE (1993) $\beta$-COP is essential for transport of protein from the endoplasmic reticulum to the Golgi in vitro. J Cell Biol 122:1155-1167

Plutner H, Cox AD, Pind S et al (1991) Rablb regulates vesicular transport between the endoplasmic reticulum and successive Golgi compartments. J Cell Biol 115:31-43

Plutner H, Davidson HW, Saraste J, Balch WE (1992) Morphological analysis of protein transport from the ER to Golgi membranes in digitonin-permeabilized cells: role of the p58- containing compartment. J Cell Biol 119:1097-1116

Popoff V, Langer JD, Reckmann I et al (2011) Several ADP-ribosylation factor (Arf) isoforms support COPI vesicle formation. J Biol Chem 286:35634-35642

Presley JF, Cole NB, Schroer TA et al (1997) ER-to-Golgi transport visualized in living cells. Nature 389:81-85

Presley JF, Smith C, Hirschberg K et al (1998) Golgi membrane dynamics. Mol Biol Cell 9:1617-1626

Presley JF, Ward TH, Pfeffer AC et al (2002) Dissection of COPI and Arf1 dynamics in vivo and role in Golgi membrane transport. Nature 417:187-193

Prydz K, Dick G, Tveit H (2008) How many ways through the Golgi maze? Traffic 9:299-304

Prydz K, Tveit H, Vedeler A, Saraste J (2013) Arrivals and departures at the plasma membrane: direct and indirect transport routes. Cell Tissue Res 352:5-20. https://doi.org/10.1007/s0044 1-012-1409-5

Pulvirenti T, Giannotta M, Capestrano M et al (2008) A traffic-activated Golgi-based signaling circuit coordinates the secretory pathway. Nat Cell Biol 10:912-922. https://doi.org/10.1038/ncb1751

Rabouille C, Klumperman J (2005) The maturing role of COPI vesicles in intra-Golgi transport. Nat Rev Mol Cell Biol 6:812-817

Rambourg A, Jackson CL, Clermont Y (2001) Three dimensional configuration of the secretory pathway and segregation of secretion granules in the yeast Saccharomyces cerevisiae. J Cell Sci 114:2231-2239

Raposo G, van Santen HM, Leijendekker R, Geuze HJ, Ploegh HL (1995) Misfolded major histocompatibility complex class I molecules accumulate in an expanded ER-Golgi intermediate compartment. J Cell Biol 131:1403-1419

Reaves B, Banting G (1992) Perturbation of the morphology of the trans-Golgi network following Brefeldin A treatment: redistribution of a TGN-specific integral membrane protein, TGN38. J Cell Biol 116:85-94

Riedel F, Galindo A, Muschalik N, Munro S (2018) The two TRAPP complexes of metazoans have distinct roles and act on different Rab GTPases. J Cell Biol 217:601-617. https://doi. org/10.1083/jcb.201705068

Risco C, Rodríguez JR, López-Iglesias C et al (2002) Endoplasmic reticulum-Golgi intermediate compartment membranes and vimentin filaments participate in vaccinia virus assembly. $\mathbf{J}$ Virol 76:1839-1855

Rivero S, Cardenas J, Bornens M, Rios RM (2009) Microtubule nucleation at the cis-side of the Golgi apparatus requires AKAP450 and GM130. EMBO J 28:1016-1028

Robinson MS (2015) Forty years of clathrin-coated vesicles. Traffic 16:1210-1238. https://doi.org/10.1111/tra.12335

Roboti P, Sato K, Lowe M (2015) The golgin GMAP-210 is required for efficient membrane trafficking in the early secretory pathway. J Cell Sci 128:1595-1606

Roghi C, Allan VJ (1999) Dynamic association of cytoplasmic dynein heavy chain 1a with the Golgi apparatus and intermediate compartment. J Cell Sci 112:4673-4685

Roth J, Zuber C (2017) Quality control of glycoprotein folding and ERAD: the role of N-glycan handling, EDEM1 and OS-9. Histochem Cell Biol 147:269-284. https://doi.org/10.1007/s0041 8-016-1513-9

Russo AJ, Mathiowetz AJ, Hong S, Welch MD, Campellone KG (2016) Rab1 recruits WHAMM during membrane remodeling but limits actin nucleation. Mol Biol Cell 27:967-978. https:// doi.org/10.1091/mbc.E15-07-0508

Sáenz JB, Sun WJ, Chang JW et al (2009) Golgicide A reveals essential roles for GBF1 in Golgi assembly and function. Nat Chem Biol 5:157-165

Sandvig K, Garred O, Prydz K, Kozlov JV, Hansen SH, van Deurs B (1992) Retrograde transport of endocytosed Shiga toxin to the endoplasmic reticulum. Nature 358:510-512

Sannerud R, Saraste J, Goud B (2003) Retrograde traffic in the biosynthetic-secretory route: pathways and machinery. Curr Opin Cell Biol 15:438-445

Sannerud R, Marie M, Nizak C et al (2006) Rab1 defines a novel pathway connecting the pre-Golgi intermediate compartment with the cell periphery. Mol Biol Cell 17:1514-1526

Saraste J (2016) Spatial and functional aspects of ER-Golgi Rabs and tethers. Front Cell Dev Biol 4:28. https://doi.org/10.3389/ fcell.2016.00028

Saraste J, Goud B (2007) Functional symmetry of endomembranes. Mol Biol Cell 18:1430-1436

Saraste J, Hedman K (1983) Intracellular vesicles involved in the transport of Semliki Forest virus membrane proteins to the cell surface. EMBO J 2:2001-2006 
Saraste J, Kuismanen E (1984) Pre- and post-Golgi vacuoles operate in the transport of Semliki Forest virus membrane glycoproteins to the cell surface. Cell 38:535-549

Saraste J, Kuismanen E (1992) Pathways of protein sorting and membrane traffic between the rough endoplasmic reticulum and the Golgi complex. Semin Cell Biol 3:343-355

Saraste J, Marie M (2016) Intermediate compartment: a sorting station between the endoplasmic reticulum and the Golgi apparatus. In: Bradshaw RA, Stahl PD (eds) Encyclopedia of cell biology vol. 2, pp 168-182

Saraste J, Svensson K (1991) Distribution of the intermediate elements operating in ER to Golgi transport. J Cell Sci 100:415-430

Saraste J, Palade GE, Farquhar MG (1986) Temperature-sensitive steps in the transport of secretory proteins through the Golgi complex in exocrine pancreatic cells. Proc Natl Acad Sci USA 83:6425-6429

Saraste J, Palade GE, Farquhar MG (1987) Antibodies to rat pancreas Golgi subfractions: Identification of a $58 \mathrm{kDa}$ cis-Golgi protein. J Cell Biol 105:2021-2029

Saraste J, Lahtinen U, Goud B (1995) Localization of the small GTPbinding protein Rab1 to early compartments of the secretory pathway. J Cell Sci 108:1541-1552

Saraste J, Dale HA, Bazzocco S, Marie M (2009) Emerging new roles of the pre-Golgi intermediate compartment in biosynthetic-secretory trafficking. FEBS Lett 583:3804-3810

Satoh M, Hirayoshi K, Yokota S, Hosokawa N, Nagata K (1996) Intracellular interaction of collagen-specific stress protein HSP47 with newly synthesized procollagen. J Cell Biol 133:469-483

Satoh A, Wang Y, Malsam J, Beard MB, Warren G (2003) Golgin-84 is a Rab1 binding partner involved in Golgi structure. Traffic 4:153-161

Scales SJ, Pepperkok R, Kreis TE (1997) Visualization of ER-to-Golgi transport in living cells reveals a sequential mode of action for COPII and COPI. Cell 90:1137-1148

Schindler R, Itin C, Zerial M, Lottspeich F, Hauri HP (1993) ERGIC53, a membrane protein of the ER-Golgi intermediate compartment, carries an ER retention motif. Eur J Cell Biol 61:1-9

Schotman H, Karhinen L, Rabouille C (2008) dGRASP-mediated noncanonical integrin secretion is required for Drosophila epithelial remodeling. Dev Cell 14:171-182. https://doi.org/10.1016/j. devcel.2007.12.006

Schweizer A, Fransen JA, Bächi T, Ginsel L, Hauri HP (1988) Identification, by a monoclonal antibody, of a $53-\mathrm{kD}$ protein associated with a tubulo-vesicular compartment at the cis-side of the Golgi apparatus. J Cell Biol 107:1643-1653

Schweizer A, Fransen JA, Matter K et al (1990) Identification of an intermediate compartment involved in protein transport from endoplasmic reticulum to Golgi apparatus. Eur J Cell Biol 53:185-196

Semenza JC, Hardwick KG, Dean N, Pelham HR (1990) ERD2, a yeast gene required for the receptor-mediated retrieval of luminal ER proteins from the secretory pathway. Cell 61:1349-1357

Sengupta P, Satpute-Krishnan P, Seo AY, Burnette DT, Patterson GH, Lippincott-Schwartz J (2015) ER trapping reveals Golgi enzymes continually revisit the ER through a recycling pathway that controls Golgi organization. Proc Natl Acad Sci USA 112:E6752E6761. https://doi.org/10.1073/pnas.1520957112

Shen X, Xu KF, Fan Q, Pacheco-Rodriguez G, Moss J, Vaughan M (2006) Association of brefeldin A- inhibited guanine nucleotideexchange protein 2 (BIG2) with recycling endosomes during transferrin uptake. Proc Natl Acad Sci USA 103:2635-2640

Shima DT, Scales SJ, Kreis TE, Pepperkok R (1999) Segregation of COPI-rich and anterograde- cargo-rich domains in endoplasmicreticulum-to-Golgi transport complexes. Curr Biol 9:821-824
Simpson JC, Nilsson T, Pepperkok R (2006) Biogenesis of tubular ER-to-Golgi transport intermediates. Mol Biol Cell 17:723-737

Sirkis DW, Aparicio RE, Schekman R (2017) Neurodegenerationassociated mutant TREM2 proteins abortively cycle between the ER and ER-Golgi intermediate compartment. Mol Biol Cell 28:2723-2733. https://doi.org/10.1091/mbc.E17-06-0423

Sitia R, Meldolesi J (1992) Endoplasmic reticulum: a dynamic patchwork of specialized subregions. Mol Biol Cell 3:1067-1072

Solis GP, Bilousov O, Koval A, Lüchtenborg A-M, Lin C, Katanaev VL (2017) Golgi-resident Goo promotes protrusive membrane dynamics. Cell 170(5):939.e24-955.e24

Stenmark H (2009) Rab GTPases as coordinators of vesicle traffic. Nat Rev Mol Cell Biol 10:513-525

Stephens DJ (2003) De novo formation, fusion and fission of mammalian COPII-coated endoplasmic reticulum exit sites. EMBO Rep 4:210-217

Stephens DJ, Pepperkok R (2001) Illuminating the secretory pathway: when do we need vesicles? J Cell Sci 114:1053-1059

Suda Y, Kurokawa K, Nakano A (2018) Regulation of ER-Golgi transport dynamics by GTPases in budding yeast. Front Cell Dev Biol 5:122. https://doi.org/10.3389/fcell.2017.00122

Szul T, Sztul E (2011) COPII and COPI traffic at the ER-Golgi interface. Physiology (Bethesda) 26:348-364. https://doi.org/10.1152/ physiol.00017.2011

Szul T, Grabski R, Lyons S et al (2007) Dissecting the role of the Arf guanine nucleotide exchange factor GBF1 in Golgi biogenesis and protein trafficking. J Cell Sci 120:3929-3940

Tang BL, Wong SH, Qi XL, Low SH, Hong W (1993) Molecular cloning, characterization, subcellular localization and dynamics of p23, the mammalian KDEL receptor. J Cell Biol 120:325-338

Thomas LL, Joiner AMN, Fromme JC (2018) The TRAPPIII complex activates the GTPase Ypt1 (Rab1) in the secretory pathway. J Cell Biol 217:283-298. https://doi.org/10.1083/jcb.201705214

Tisdale EJ, Artalejo CR (2006) Src-dependent atypical protein kinase $\mathrm{C}$ iota/lambda (aPKCiota/lambda) tyrosine phosphorylation is required for aPKCiota/lambda association with Rab2 and glyceraldehyde-3-phosphate dehydrogenase on pre-Golgi intermediates. J Biol Chem 281:8436-8442

Tisdale EJ, Plutner H, Matteson J, Balch WE (1997) p53/58 binds COPI and is required for selective transport through the early secretory pathway. J Cell Biol 137:581-593

Togawa A, Morinaga N, Ogasawara M, Moss J, Vaughan M (1999) Purification and cloning of a brefeldin A-inhibited guanine nucleotide-exchange protein for ADP-ribosylation factors. J Biol Chem 274:12308-12315

Tomás M, Martínez-Alonso E, Ballesta J, Martínez-Menárguez JA (2010) Regulation of ER-Golgi intermediate compartment tubulation and mobility by COPI coats, motor proteins and microtubules. Traffic 11:616-625

Tooze J, Hollinshead M (1992) In AtT20 and HeLa cells brefeldin A induces the fusion of tubular endosomes and changes their distribution and some of their endocytic properties. J Cell Biol 118:813-830

Tooze J, Tooze S, Warren G (1984) Replication of coronavirus MHVA59 in sac- cells: determination of the first site of budding of progeny virions. Eur J Cell Biol 33:281-293

Tooze SA, Tooze J, Warren G (1988) Site of addition of N-acetylgalactosamine to the E1 glycoprotein of mouse hepatitis virusA59. J Cell Biol 106:1475-1487

Trucco A, Polishchuk RS, Martella O et al (2004) Secretory traffic triggers the formation of tubular continuities across Golgi subcompartments. Nat Cell Biol 6:1071-1081

Tveit H, Akslen LK, Fagereng GL, Tranulis MA, Prydz K (2009) A secretory Golgi bypass route to the apical surface domain of 
epithelial MDCK cells. Traffic 10:1685-1695. https://doi.org/1 0.1111/j.1600-0854.2009.00984.x

Urbani L, Simoni RD (1990) Cholesterol and vesicular stomatitis virus $\mathrm{G}$ protein take separate routes from the endoplasmic reticulum to the plasma membrane. J Biol Chem 265:1919-1923

van Niel G, D’Angelo G, Raposo G (2018) Shedding light on the cell biology of extracellular vesicles. Nat Rev Mol Cell Biol 19:213228. https://doi.org/10.1038/nrm.2017.125

Vavassori S, Cortini M, Masui S et al (2013) A pH-regulated quality control cycle for surveillance of secretory protein assembly. Mol Cell 50:783-792

Velloso LM, Svensson K, Pettersson RF, Lindqvist Y (2003) The crystal structure of the carbohydrate-recognition domain of the glycoprotein sorting receptor p58/ERGIC-53 reveals an unpredicted metal-binding site and conformational changes associated with calcium ion binding. J Mol Biol 334:845-851

Verissimo F, Pepperkok R (2013) Imaging ER-to-Golgi transport: towards a systems view. J Cell Sci 126:5091-5100. https://doi. org/10.1242/jcs.121061

Volchuk A, Amherdt M, Ravazzola M et al (2000) Megavesicles implicated in the rapid transport of intracisternal aggregates across the Golgi stack. Cell 102:335-348

Volpicelli-Daley LA, Li Y, Zhang CJ, Kahn RA (2005) Isoform-selective effects of the depletion of ADP-ribosylation factors 1-5 on membrane traffic. Mol Biol Cell 16:4495-4508

Ward TH, Polishchuk RS, Caplan S, Hirschberg K, LippincottSchwartz J (2001) Maintenance of Golgi structure and function depends on the integrity of ER export. J Cell Biol 155:557-570

Warren G (1987) Signals and salvage sequences. Nature 327:17-18

Watson P, Forster R, Palmer KJ, Pepperkok R, Stephens DJ (2005) Coupling of ER exit tomicrotubules through direct interaction of COPII with dynactin. Nat Cell Biol 7: 48-55

Wilson DW, Lewis MJ, Pelham HR (1993) pH-dependent binding of KDEL to its receptor in vitro. J Biol Chem 268:7465-7468

Wilson BS, Nuoffer C, Meinkoth JL, McCaffery M, Feramisco JR, Balch WE, Farquhar MG (1994) A Rab1 mutant affecting guanine nucleotide exchange promotes disassembly of the Golgi apparatus. J Cell Biol 125:557-571

Winslow AR, Chen CW, Corrochano S et al (2010) $\alpha$-Synuclein impairs macroautophagy: implications for Parkinson's disease. J Cell Biol 190:1023-1037

Witte K, Schuh AL, Hegermann J (2011) TFG-1 function in protein secretion and oncogenesis. Nat Cell Biol 13:550-558. https:// doi.org/10.1038/ncb2225

Yadav S, Puthenveedu MA, Linstedt AD (2012) Golgin160 recruits the dynein motor to position the Golgi apparatus. Dev Cell 23:153165. https://doi.org/10.1016/j.devcel.2012.05.023
Yamamoto K, Fujii R, Toyofuku Y et al (2001) The KDEL receptor mediates a retrieval mechanism that contributes to quality control at the endoplasmic reticulum. EMBO J 20:3082-3091

Yamashiro DJ, Tycko B, Fluss SR, Maxfield FR (1984) Segregation of transferrin to a mildly acidic ( $\mathrm{pH} 6.5)$ para-Golgi compartment in the recycling pathway. Cell 37:789-800

Yang JS, Gad H, Lee SY (2008) A role for phosphatidic acid in COPI vesicle fission yields insights into Golgi maintenance. Nat Cell Biol 10:1146-1153. https://doi.org/10.1038/ncb1774

Yang JS, Valente C, Polishchuk RS (2011) COPI acts in both vesicular and tubular transport. Nat Cell Biol 13:996-1003. https://doi. org/10.1038/ncb2273

Ying M, Flatmark T, Saraste J (2000) The p58-positive pre-Golgi intermediates consist of distinct subpopulations of particles that show differential binding of COPI and COPII coats and contain vacuolar $\mathrm{H}^{+}$-ATPase. J Cell Sci 113:3623-3638

Yoo JS, Moyer BD, Bannykh S et al (2002) Non-conventional trafficking of the cystic fibrosis transmembrane conductance regulator through the early secretory pathway. J Biol Chem 277:11401-11409

Zanetti G, Pahuja KB, Studer S, Shim S, Schekman R (2012) COPII and the regulation of protein sorting in mammals. Nat Cell Biol 14:20-28

Zhao X, Claude A, Chun J et al (2006) GBF1, a cis-Golgi and VTCslocalized ARF-GEF, is implicated in ER-to-Golgi protein traffic. J Cell Sci 119:3743-3753

Zheng C, Page RC, Das V et al (2013) Structural characterization of carbohydrate binding by LMAN1 protein provides new insight into the endoplasmic reticulum export of factors V (FV) and VIII (FVIII). J Biol Chem 288:20499-20509

Zoppino FC, Militello RD, Slavin I, Alvarez C, Colombo MI (2010) Autophagosome formation depends on the small GTPase Rab1 and functional ER exit sites. Traffic 11:1246-1261

Zuber C, Fan J, Guhl B et al (2001) Immunolocalization of UDPglucose:glycoprotein glucosyltransferase indicates involvement of pre-Golgi intermediates in protein quality control. Proc Natl Acad Sci USA 98:10710-10715

Zuber C, Fan JY, Guhl B, Roth J (2004) Misfolded proinsulin accumulates in expanded pre-Golgi intermediates and endoplasmic reticulum subdomains in pancreatic beta cells of Akita mice. FASEB J 18:917-919

Zurzolo C, Simons K (2016) Glycosylphosphatidylinositol-anchored proteins: Membrane organization and transport. Biochim Biophys Acta 1858:632-639. https://doi.org/10.1016/j.bbame m.2015.12.018 